\title{
Maintenance Treatment for Recurrent Ovarian Carcinoma - Evidence Supporting the Efficacy and Safety of PARP Inhibitors
}

\author{
Robert L Coleman ${ }^{1}$ and Jonathan A Ledermann² \\ 1. Department of Gynecologic Oncology and Reproductive Medicine, University of Texas MD Anderson Cancer Center, Houston, Texas, USA; \\ 2. UCL Cancer Institute and University College London Hospitals, London, UK
}

W hile recent advances in treatment mean that women with ovarian cancer are living longer, many eventually experience disease relapse highlighting the need for new treatments that can extend progression-free survival (PFS). The PARP inhibitors olaparib, niraparib and rucaparib have been approved by the US Food and Drug Administration and the European Commission and are currently available for the maintenance treatment of patients with recurrent epithelial ovarian, fallopian tube or primary peritoneal cancer who are in a complete or partial response to platinum-based chemotherapy. Here, we review the efficacy and safety data from the key clinical trials supporting the approvals for these treatments as second-line maintenance therapies, including Study 19, SOLO2/ ENGOT-OV21 (olaparib), NOVA/ENGOT-OV16 (niraparib) and ARIEL3 (rucaparib). Across trials, PFS was improved with PARP inhibitor maintenance treatment versus placebo in patients with a BRCA mutation. However, evidence from some of the trials shows that a wider group of patients can benefit from PARP inhibitor maintenance treatment including those with or without homologous recombination deficient tumours. The safety profile for olaparib, niraparib and rucaparib was generally similar across trials with haematological and gastrointestinal adverse events and fatigue/asthenia being the most common. As evidenced by the significant improvements in PFS and manageable safety profiles in these trials, PARP inhibitors represent a new standard of care for recurrent ovarian cancer following platinum-based chemotherapy and delay the need for further chemotherapy.

\section{Keywords}

BRCA mutation, homologous recombination deficiency, maintenance treatment, niraparib, olaparib, PARP inhibitor, recurrent ovarian carcinoma, rucaparib

Disclosures: Robert L Coleman reports grants from AstraZeneca, Roche/ Genentech, Janssen, OncoMed, Millennium, Merck, Clovis Oncology, Esperance, and AbbVie and reports serving as an advisor to AstraZeneca, Roche/

Genentech, Janssen, OncoMed, Millennium, Merck, Clovis Oncology, Esperance, Tesaro, GamaMabs, Pfizer, Genmab, Gradalis, Bayer and AbbVie. Jonathan A Ledermann has served in an advisory role and/or on a speakers' bureau for Clovis Oncology, AstraZeneca, Tesaro Inc, Merck/MSD, Seattle Genetics, Roche and Pfizer and received research grants from Astrazeneca and Merck/MSD.

Acknowledgement: Medical writing support, including preparation of the drafts under the guidance of the authors, was provided by James Gilbart of Touch Medical Communication and Nathan Yardley of Ashfield Healthcare Communications and was funded by Clovis Oncology.

Review Process: Double-blind peer review.

Compliance with Ethics: This study involves a review of the literature and did not involve any studies with human or animal subjects performed by any of the authors.

Authorship: The named authors meet the criteria of the International

committee of Medical Journal Editors for authorship for this manuscript,

take responsibility for the integrity of the work as a whole and

have given final approval for the version to be published.

Received: 2 April 2019

Accepted: 12 July 2019

Citation: European Oncology \& Haematology. 2019;15(1):29-40

Corresponding Author: Robert L Coleman, Department of Gynecologic Oncology and Reproductive Medicine, University of Texas MD Anderson Cancer Center, Houston, Texas 77030, USA. E: rcoleman@mdanderson.org

Support: The publication of this article was supported

by Clovis Oncology. The views and opinions expressed in the article are

those of the authors and not necessarily those of Clovis Oncology.
Worldwide, ovarian cancer is the seventh most common cancer and the eighth most common cause of cancer death in women. ${ }^{1}$ The GLOBOCAN study estimated there were 239,000 new cases in 2012 and 152,000 deaths due to this disease. There are nearly 600,000 women living within 5 years of an ovarian cancer diagnosis. 'In the EU, age-adjusted ovarian cancer mortality rates decreased 10\% between 2002-12, from 5.8 to 5.2 per 100,000. During this same time period in the USA, the decline was $16 \%$, to 4.9 per 100,000 in 2012. ' However, over the same time period, the prevalence of the disease has increased, with a sharp increase in more recent years (Figure 1). ${ }^{2-4}$ This increase in prevalence may be attributable to advances in ovarian cancer treatment, which leads to more lines of treatment being given to prolong survival without increasing the rate of cure. The majority of patients with advanced ovarian cancer eventually relapse, so there is a substantial need for new treatments. One potential strategy to reduce the likelihood of recurrence is to use maintenance therapy after chemotherapy to extend the response to treatment and delay the next line of chemotherapy. Such extended treatment is difficult to achieve with chemotherapy due to cumulative toxicities, so other maintenance therapies are needed.

Poly(ADP-ribose) polymerase (PARP) inhibitors are an intriguing new class of therapeutic agents for ovarian cancer. Inhibition of PARP enzymes slows or abolishes the repair of single-strand breaks in DNA and leads to the formation of double-strand breaks. ${ }^{5}$ Double-strand breaks in DNA are normally rectified through the homologous recombination repair (HRR) pathway. ${ }^{6-8}$ In cells with homologous recombination deficiency (HRD) such as those with a mutation in BRCA1 or BRCA2 (BRCA), double-strand breaks cannot be efficiently repaired, resulting in cell death via a process termed 'synthetic sickness' or 'synergistic lethality'. 9 A therapeutic response to PARP inhibitors has been shown in patients with ovarian tumours with mutations in BRCA or other HRR genes (e.g., RAD51, BARD1, PALB2 and others), and in ovarian tumours with high loss of heterozygosity ( $(\mathrm{OH})$, a genomic signature associated with HRD. ${ }^{10-21}$ However, clinical evidence 
Figure 1: Estimated prevalence and incidence of ovarian cancer in the USA from 2001-2016

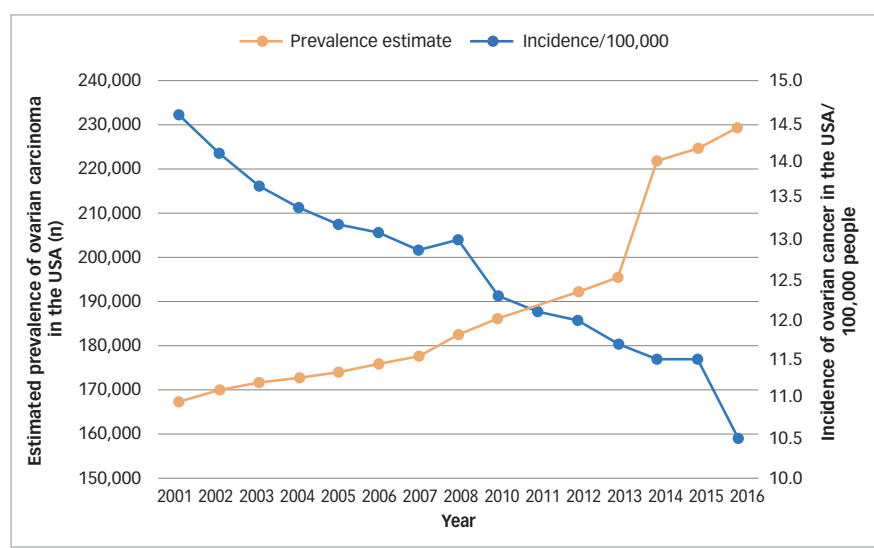

Source: National Cancer Institute Surveillance, Epidemiology and End Results Program (SEER) Cancer Statistics Review (CSR) 1975-2015 - Ovary Section and archival CSRS from 2001-2014. ${ }^{2,4}$

has emerged showing that patients with ovarian cancer can also receive clinical benefit from PARP inhibitors regardless of their assay-determined HRD status. ${ }^{10,11}$

Three PARP inhibitors, olaparib (Lynparza ${ }^{\circledR}$, AstraZeneca, Cambridge, UK), niraparib (Zejula ${ }^{\circledR}$, Tesaro, a GlaxoSmithKline company, Waltham, Massachusetts, USA) and rucaparib (Rubraca ${ }^{\circledR}$, Clovis Oncology, Boulder, Colorado, USA) have shown promising results when used as maintenance treatment of recurrent platinum-sensitive ovarian cancer after completion of platinum-based chemotherapy. ${ }^{9-11,13,22-24}$ In the USA, each of these agents has US Food and Drug Administration (FDA) approval in this setting. ${ }^{25-27}$ Similarly, in Europe, olaparib, niraparib and more recently, rucaparib are now approved for the maintenance treatment of adult patients with platinum-sensitive relapsed high grade serous epithelial ovarian, fallopian tube, or primary peritoneal cancer who are in response (complete or partial response) to platinum-based chemotherapy. ${ }^{28,29}$ Olaparib is also approved in the USA for the treatment of recurrent ovarian cancer occurring in germline BRCA (gBRCA) mutation carriers who have had three or more prior lines of therapy, ${ }^{26}$ and rucaparib is approved in both the USA and Europe for the treatment of recurrent ovarian cancer following two prior lines of therapy in patients who have a germline BRCA mutation or in patients who have a somatic BRCA (SBRCA) mutation. ${ }^{27,29}$

This review summarises the findings from the pivotal clinical trials of olaparib, niraparib and rucaparib that support their use as maintenance therapy for recurrent ovarian cancer. We highlight the key differences in the clinical trial designs and examine the distinct efficacy and safety profiles of each PARP inhibitor.

\section{Key clinical trial data supporting poly(ADP- ribose) polymerase inhibitors as maintenance treatments for recurrent ovarian cancer}

PARP inhibition as maintenance therapy for recurrent ovarian cancer has been investigated with olaparib in Study 19 and SOLO2/ENGOTOV21, 13,15 niraparib in NOVA/ENGOT-OV16 ${ }^{10}$ and rucaparib in ARIEL3 ${ }^{11}$ (see end of text for study name definitions). Results from these trials are not directly comparable because of the different study designs and patient populations studied. For example, in NOVA, the primary endpoint was blinded independent central review (BICR)-assessed progressionfree survival (PFS), whilst in Study 19 and ARIEL3 the primary endpoint was investigator-assessed PFS. Furthermore, Study 19 and ARIEL3 both examined the primary endpoint in prospectively defined populations that included all patients, whereas NOVA prospectively analysed PFS in distinct subgroups of patients based on the presence/absence of a gBRCA mutation and SOLO2 was limited to women carrying a germline or somatic mutation in BRCA1/2. Notably, in NOVA, patients with a SBRCA mutation were included in the non-gBRCA cohorts, which is unique to this study. ${ }^{10}$

Differences in the patient populations for each study include the proportion of patients with a germline or somatic BRCA mutation (Study 19, 51\%; SOLO2, 97\%; NOVA, 45\%; ARIEL3, 35\%). ${ }^{10,11,13,15}$ While the phase III NOVA and ARIEL3 trials of niraparib and rucaparib, respectively, included all-comers, the only all-comer data for olaparib in the maintenance setting comes from the randomised phase \| trial, Study 19. The proportion of patients with a complete response to prior platinumbased chemotherapy also differed across studies (Study 19, 45\%; SOLO2, 46\%; NOVA, 51\%; ARIEL3, 34\%). ${ }^{10,11,13,15}$ In contrast to NOVA, enrolment in SOLO2 and ARIEL3 was not limited by target lesion size for patients with a partial response to previous platinum-based chemotherapy and thus these trials recruited more patients with bulky residual disease $(>2 \mathrm{~cm}$ ) at baseline (SOLO2, 15\%; ARIEL3, 19\%). ${ }^{10,11,13,15}$ An overview of study designs and endpoints for these trials is given in Table 1, key efficacy data are provided in Figures 2 and 3 , and a summary of safety data is provided Figure 4. It should be noted that the presentation of data from different studies in these figures is for interest only; the studies included populations with different mutation profiles and had differing inclusion/ exclusion criteria and so the results are not directly comparable.

\section{Olaparib}

Study 19 was a randomised phase ॥ evaluation of olaparib capsules (400 mg twice daily [BID]) used as a maintenance treatment of patients $(\mathrm{N}=265)$ with platinum-sensitive recurrent ovarian cancer. ${ }^{13}$ The primary endpoint was investigator-assessed PFS from randomisation, which was significantly longer with olaparib than placebo (median 8.4 months versus 4.8 months; hazard ratio [HR], 0.35; 95\% confidence interval [Cl], 0.25-0.49; $\mathrm{p}<0.001$; Figure 2A). This advantage was seen across all subgroups that were evaluated (BRCA mutation status, age, race [White/ non-Jewish], baseline response, and time to progression on penultimate platinum-based regimen). A retrospective analysis of investigatorassessed PFS according to BRCA status, completed after publication of the trial, showed that median PFS in the subgroup with BRCA mutations (gBRCA and SBRCA; approximately 50\% of the women) for olaparib versus placebo was 11.2 months versus 4.3 months ( $\mathrm{HR}, 0.18$; 95\% Cl, 0.10-0.31; Figure $2 A$ ). In the subgroup with wild-type BRCA (wtBRCA), median PFS was 7.4 months versus 5.5 months ( $\mathrm{HR}, 0.54$; $95 \% \mathrm{Cl}, 0.34-0.85$; Figure $2 \mathrm{~A}) .{ }^{14}$ For the secondary endpoint of time to progression according to Response Evaluation Criteria In Solid Tumours (RECIST) version $1.1^{30}$ or cancer antigen 125 (CA-125) level (whichever occurred first), the median was 8.3 months in the olaparib arm compared to 3.7 months in the placebo arm (HR, 0.35; 95\% Cl, 0.25-0.47). ${ }^{13}$ The objective response rate (ORR) at 24 weeks (a secondary endpoint) was higher with olaparib (12\%; $7 / 57$ patients with measurable disease at baseline) than with placebo (4\%; $2 / 48)^{13}$ as was the disease-control rate (secondary endpoint; 53\% [72/136] versus $25 \%$ [32/129]). ${ }^{31}$

In the overall study population, the most notable adverse events (AEs) were gastrointestinal in nature (nausea [olaparib, 68\% versus placebo, $35 \%$ ] and vomiting [32\% versus 14\%]) but fatigue (49\% versus 38\%) was also common. Most AEs were low grade but the commonest AEs of grade $\geq 3$ (olaparib versus placebo) included fatigue (7\% versus $3 \%$ ), 
Table 1: Key features and differences between designs of pivotal clinical trials on olaparib, niraparib and rucaparib in the maintenance treatment of ovarian carcinoma

\begin{tabular}{|c|c|c|c|c|}
\hline & Study $19^{13,45}(\mathrm{~N}=265)$ & SOLO2/ENGOT-OV21 $1^{15}(\mathrm{~N}=295)$ & NOVA/ENGOT-OV16 $6^{10}(\mathrm{~N}=553)$ & ARIEL3 ${ }^{11}(\mathrm{~N}=564)$ \\
\hline Treatments & Olaparib versus placebo (1:1) & Olaparib versus placebo $(2: 1)$ & Niraparib versus placebo $(2: 1)$ & Rucaparib versus placebo (2:1) \\
\hline Mutation types & 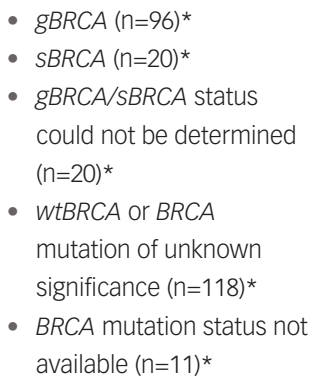 & $\begin{array}{l}\text { - } \text { gBRCA }(\mathrm{n}=286) \\
\text { - } \text { wtBRCA }(\mathrm{n}=2) \\
\text { - } \text { BRCA mutation not confirmed } \\
\text { to be deleterious/of unknown } \\
\text { significance }(\mathrm{n}=7)\end{array}$ & $\begin{array}{l}\text { - } \operatorname{gBRCA}(\mathrm{n}=203) \\
\text { - } \operatorname{sBRCA}(\mathrm{n}=47) \\
\text { - } \text { wtBRCA/HRD-positive }(\mathrm{n}=115) \\
\text { - } \text { HRD-negative }(\mathrm{n}=134) \\
\text { - } \text { HRD not determined }(\mathrm{n}=54)\end{array}$ & $\begin{array}{ll}\text { - } & g B R C A(n=130) \\
\text { - } & \text { sBRCA }(\mathrm{n}=56) \\
\text { - } & \text { wtBRCA/high LOH }(\mathrm{n}=158) \\
\text { - } & \text { wtBRCA/low LOH }(\mathrm{n}=161) \\
\text { - } & \text { wtBRCA/LOH indeterminate } \\
& (\mathrm{n}=49) \\
\text { - } & \text { Germline or somatic status } \\
& \text { unknown ( } \mathrm{n}=10)\end{array}$ \\
\hline $\begin{array}{l}\text { Prospectively } \\
\text { defined analysis } \\
\text { groups }\end{array}$ & - All patients ( $\mathrm{N}=265)$ & - All patients ( $\mathrm{N}=295)$ & $\begin{array}{l}\text { - } \text { gBRCA ( } \mathrm{n}=203) \\
\text { non-gBRCA ( } \mathrm{n}=350 \text {; includes } \\
\text { HRD-negative, and HRD not } \\
\text { determined) } \\
\text { - } \text { non-gBRCA with HRD ( } \mathrm{n}=162 \text {; } \\
\text { only } \text { SBRCA and wtBRCA/ } \\
\text { HRD-positive) }\end{array}$ & $\begin{array}{l}\text { - } \text { BRCA mutant ( } \mathrm{n}=196 \text {; includes } \\
\text { gBRCA and } S B R C A) \\
\text { - } \text { HRD cohort ( } \mathrm{n}=354 \text {; includes } \\
\text { gBRCA, SBRCA and wtBRCA/ } \\
\text { high LOH) } \\
\text { - } \text { ITT population ( } \mathrm{N}=564 \text {; } \\
\text { includes all patients) }\end{array}$ \\
\hline $\begin{array}{l}\text { Primary } \\
\text { endpoint }\end{array}$ & Investigator-assessed PFS & Investigator-assessed PFS & BICR-assessed PFS & Investigator-assessed PFS \\
\hline $\begin{array}{l}\text { Secondary } \\
\text { endpoints }\end{array}$ & $\begin{array}{l}\text { - } \text { Time to progression per } \\
\text { RECIST or CA-125 level } \\
\text { - ORR } \\
\text { - Disease-control rate } \\
\text { - Percentage change from } \\
\text { baseline in size of target } \\
\text { tumour } \\
\text { - Disease-related } \\
\text { symptoms and HRQoL } \\
\text { - Safety }\end{array}$ & $\begin{array}{l}\text { - Time to first subsequent } \\
\text { - } \text { - PFS2 } \\
\text { - Time to second subsequent } \\
\text { therapy or death } \\
\text { - Time to discontinuation or } \\
\text { death } \\
\text { - Time to earliest progression } \\
\text { or death } \\
\text { - OS } \\
\text { - Safety and tolerability } \\
\text { - HRQoL }\end{array}$ & $\begin{array}{l}\text { - Patient-reported outcomes } \\
\text { - } \text { Chemotherapy-free interval } \\
\text { - Time to first subsequent therapy } \\
\text { - PFS2 } \\
\text { - Time to second subsequent } \\
\text { therapy } \\
\text { - OS }\end{array}$ & $\begin{array}{l}\text { - } \text { BICR-assessed PFS } \\
\text { - Time to worsening in FOSI-18 } \\
\text { DRS-P subscale } \\
\text { - Time to worsening in FOSI-18 } \\
\text { total score } \\
\text { - } \text { OS } \\
\text { - Safety } \\
\text { - Population PK modelling }\end{array}$ \\
\hline Assessments & $\begin{array}{l}\text { - } \text { CT scans every } 12 \text { weeks } \\
\text { Patient-reported } \\
\text { outcomes were assessed } \\
\text { using FACT-O and FOSI } \\
\text { questionnaires } \\
\text { - Safety was assessed with } \\
\text { AEs, laboratory testing, } \\
\text { vital signs and physical } \\
\text { examinations }\end{array}$ & $\begin{array}{l}\text { - CT or MRI scans every } \\
12 \text { weeks until week } 72, \\
\text { and then every } 24 \text { weeks } \\
\text { thereafter until objective } \\
\text { disease progression; after } \\
\text { disease progression, patients } \\
\text { were followed every } 12 \text { weeks } \\
\text { for second progression and } \\
\text { survival } \\
\text { - Safety was assessed with AEs, } \\
\text { laboratory testing, vital signs } \\
\text { and physical examinations } \\
\text { - HRQoL was assessed using } \\
\text { TOI-FACT-O questionnaire }\end{array}$ & $\begin{array}{l}\text { - } \text { CT or MRI at baseline, every } \\
8 \text { weeks through cycle 14, then } \\
\text { every } 12 \text { weeks until treatment } \\
\text { discontinuation } \\
\text { - Safety was assessed with AEs, } \\
\text { laboratory testing, vital signs and } \\
\text { physical examinations } \\
\text { - Patient-reported monitoring } \\
\text { included FOSI and EQ-5D-5L } \\
\text { questionnaires }\end{array}$ & $\begin{array}{l}\text { - CT and/or 'other' imaging every } \\
12 \text { weeks during treatment and } \\
\text { after treatment for patients who } \\
\text { discontinued for a reason other } \\
\text { than progression } \\
\text { - Safety assessed with AEs, } \\
\text { laboratory testing, vital signs } \\
\text { and physical examinations } \\
\text { - FOSI-18 questionnaire (for patient- } \\
\text { reported outcomes) }\end{array}$ \\
\hline $\begin{array}{l}\text { Additional } \\
\text { subgroups } \\
\text { examined }\end{array}$ & $\begin{array}{l}\text { - } \text { BRCA mutation status } \\
\text { - } \text { Jewe } \\
\text { ancestry or non-Jewish } \\
\text { - } \text { Response status at } \\
\text { baseline } \\
\text { - } \text { Time to progression from } \\
\text { the start of penultimate } \\
\text { platinum-based regimen }\end{array}$ & $\begin{array}{l}\text { - Previous bevacizumab } \\
\text { - Presence of a confirmed } \\
\text { BRCA mutation }\end{array}$ & $\begin{array}{l}\text { - } \text { Age } \\
\text { - } \text { Race } \\
\text { - } \text { Region } \\
\text { - } \text { enime to progression before } \\
\text { - } \text { Bevacizumab use } \\
\text { - } \text { Best response to platinum-based } \\
\text { - } \text { chemotherapy } \\
\text { - } \text { latinum-based chemotherapy in } \\
\text { - } \text { Number of previous platinum } \\
\text { - } \text { regimens } \\
\text { rumber of prior chemotherapy } \\
\text { regimens }\end{array}$ & $\begin{array}{l}\text { - } \text { Age } \\
\text { - } \text { Race } \\
\text { - } \text { Measurable disease at baseline } \\
\text { - } \text { Previous disease at baseline } \\
\text { - } \text { Number of platinum regimens } \\
\text { - } \text { Time to progression of previous } \\
\text { - } \text { platinum regimen } \\
\text { - } \text { chember of previous } \\
\text { - } \text { Response to last platinum-based } \\
\text { chemotherapy }\end{array}$ \\
\hline
\end{tabular}


Table 1: Cont.

\begin{tabular}{|c|c|c|c|c|}
\hline $\begin{array}{l}\text { Stratification } \\
\text { variables }\end{array}$ & $\begin{array}{l}\text { - Time to progression } \\
\text { after completion of the } \\
\text { penultimate platinum } \\
\text { regimen (6-12 months } \\
\text { versus } \geq 12 \text { months) } \\
\text { - } \text { Best response to } \\
\text { last platinum-based } \\
\text { chemotherapy (complete } \\
\text { or partial) } \\
\text { - } \text { Ancestry (Jewish versus } \\
\text { non-Jewish) }\end{array}$ & $\begin{array}{l}\text { - } \text { Response to previous } \\
\text { chemotherapy (complete } \\
\text { versus partial) } \\
\text { - Length of platinum-free } \\
\text { interval (6-12 months } \\
\text { versus } \geq 12 \text { months) }\end{array}$ & $\begin{array}{l}\text { - Time to progression after } \\
\text { completion of the penultimate } \\
\text { platinum regimen (6-12 months } \\
\text { versus } \geq 12 \text { months) } \\
\text { - Use of bevacizumab in } \\
\text { conjunction with penultimate } \\
\text { or last platinum regimen } \\
\text { - Best response during last } \\
\text { platinum regimen (complete } \\
\text { or partial) }\end{array}$ & $\begin{array}{l}\text { - Homologous recombination } \\
\text { repair gene mutation status } \\
\text { (mutation in BRCA1 or BRCA2, } \\
\text { mutation in non-BRCA gene } \\
\text { associated with homologous } \\
\text { recombination or no mutation } \\
\text { in BRCA or a homologous } \\
\text { recombination gene) } \\
\text { - Time to progression after } \\
\text { penultimate platinum-based } \\
\text { chemotherapy (6-12 months } \\
\text { versus } \geq 12 \text { months) } \\
\text { - Best response to last platinum- } \\
\text { based chemotherapy (complete } \\
\text { or partial) }\end{array}$ \\
\hline $\begin{array}{l}\text { Assessment of } \\
B R C A / H R D\end{array}$ & $\begin{array}{l}\text { - } \text { Case report forms } \\
\text { documenting previous } \\
\text { local gBRCA testing } \\
\text { - } \text { Retrospective BRAC } \\
\text { analysis testing (Myriad } \\
\text { Genetics, Salt Lake City } \\
\text { UT, USA) for gBRCA } \\
\text { - } \text { Retrospective NGS assay } \\
\text { (Foundation Medicine, } \\
\text { Cambridge, MA, USA) } \\
\text { for SBRCA }\end{array}$ & $\begin{array}{l}\text { - BRAC analysis testing (Myriad } \\
\text { Genetics, Salt Lake City } \\
\text { UT, USA) - assessed BRCA } \\
\text { mutation only }\end{array}$ & $\begin{array}{l}\text { - } \text { myChoice }{ }^{\circledR} \text { HRD test - (Myriad } \\
\text { Genetics, Salt Lake City UT, USA) }\end{array}$ & $\begin{array}{l}\text { - T5 NGS assay (Foundation } \\
\text { Medicine, Cambridge, MA, USA) }\end{array}$ \\
\hline
\end{tabular}

In all four studies, patients had platinum-sensitive recurrent ovarian carcinoma.

* Mutation status as reported in updated analysis of Study 19 data. ${ }^{45}$

$A E=$ adverse event; $B I C R=$ blinded independent central review; $C A-125=$ cancer antigen 125; $C T=$ computer tomography; DRS-P = disease-related symptoms-physical;

FACT-O = Functional Assessment of Cancer Therapy-Ovarian; FOSI-18 = FACT-Ovarian Symptom Index 18; gBRCA = germline BRCA1 or BRCA2; HRD = homologous

recombination deficiency; $H R Q O L=$ health-related quality of life; $I T T=$ intent-to-treat; $L O H=I O S S$ of heterozygosity; MA = Massachusetts; $M R I=$ magnetic resonance imaging;

$N G S=$ next-generation sequencing; ORR = objective response rate; OS = overall survival; $P F S 2=$ time to second progression or death; $P F S=$ progression-free survival; $P K=$

pharmacokinetics; RECIST = Response Evaluation Criteria in Solid Tumors; SBRCA = somatic BRCA1 or BRCA2; TOI-FACT-O = Trial OutCome Index derived from the FACT-O;

UT = Utah; wtBRCA = wild-type BRCA1 or BRCA2.

anaemia ( $5 \%$ versus $1 \%)$, back pain ( $2 \%$ versus $0 \%)$, diarrhoea ( $2 \%$ versus $2 \%)$, nausea (2\% versus $0 \%$ ) and vomiting (2\% versus $1 \%){ }^{13}$

In Study 19, health-related quality of life (QoL) was assessed using the Functional Assessment of Cancer Therapy-Ovarian (FACT-O) questionnaire total score as well as the Trial Outcome Index (TOl; a subset of 26 FACT-O items) and the FACT-O Symptoms Index (FOSI; a subset of eight FACT-O items). No significant differences were observed between arms in the rates of score improvement across the TOI (odds ratio [OR], $1.14 ; 95 \% \mathrm{Cl}, 0.58-2.24 ; p=0.7)$, FOSI (OR, 1.22; 95\% Cl, 0.60-2.51; $p=0.59)$ and FACT-O (OR, 1.17; 95\% Cl, 0.60-2.27; $\mathrm{p}=0.65) .{ }^{32}$

A more recent long-term follow-up of overall survival (OS) findings in Study 19 (at 79\% data maturity) showed a favourable result for olaparib over placebo for OS (HR, 0.73; 95\% Cl, 0.55-0.95; nominal $\mathrm{p}=0.021$ ), irrespective of BRCA1/2 mutation status. ${ }^{33}$ However, this study was not designed to show a statistically significant difference in $O S$; the $p$ values did not meet the pre-set criterion for significance $(p<0.0095)$ and therefore, the favourable treatment effect reported for os should only be regarded as descriptive. It is noteworthy that this follow-up showed that $24 \%$ of patients received olaparib maintenance therapy for $>2$ years and $11 \%$ received this treatment for $>6$ years, and this includes patients with and without BRCA mutations. This analysis identified no new tolerability signals during long-term treatment and AEs were generally low grade. The incidence of discontinuations due to AEs was low (6\%).

Further pivotal data supporting olaparib in the maintenance treatment of recurrent ovarian cancer comes from the phase III SOLO2 study, in which patients $(\mathrm{N}=295)$ with platinum-sensitive recurrent ovarian cancer and $a$ BRCA mutation were treated with olaparib $(n=196,300$ mg tablets
BID) or placebo $(n=99) .{ }^{15}$ Median investigator-assessed PFS (primary endpoint) was significantly longer with olaparib $(19.1$ months [95\% Cl, 16.3-25.7]) than with placebo (5.5 months [95\% Cl, 5.2-5.8]; HR, 0.30; $95 \% \mathrm{Cl}, 0.22-0.41 ; \mathrm{p}<0.0001$; Figure $2 \mathrm{~B}$ ). In a sensitivity analysis of PFS by BICR, median PFS was also longer with olaparib (30.2 months [95\% $\mathrm{Cl}, 19.8-$ not reached]) than with placebo (5.5 months [95\% Cl, 4.8-5.6]; $\mathrm{HR}, 0.25 ; 95 \% \mathrm{Cl}, 0.18-0.35 ; \mathrm{p}<0.0001$; Figures $2 B$ and $3 A$ ). Compared to placebo, olaparib improved outcomes for secondary endpoints, including median time to first subsequent therapy or death (TFST; 27.9 months versus 7.1 months; $\mathrm{HR}, 0.28 ; 95 \% \mathrm{Cl}, 0.21-0.38$ ), median time to second progression or death (PFS2 [a parameter that indicates duration of survival on subsequent therapy following progression on maintenance therapy]; not reached versus 18.4 months; HR, 0.50; 95\% $\mathrm{Cl}, 0.34-0.72)$, median time to second subsequent therapy or death (TSST; not reached versus 18.2 months; HR, 0.37 ; $95 \% \mathrm{Cl}, 0.26-0.53$ ), median time to study discontinuation or death (19.4 months versus 5.6 months; HR, $0.31 ; 95 \% \mathrm{Cl}, 0.23-0.42)$ and median time to earliest progression or death (16.9 months versus 4.9 months; HR, 0.30; 95\% $\mathrm{Cl}, 0.23-0.41){ }^{15}$ Data for the secondary endpoint of OS were immature (24\% maturity) with medians not reached for either group (HR, 0.80; $95 \% \mathrm{Cl}, 0.50-1.31) .{ }^{15,34}$

A recent analysis of tumour responses in the SOLO2 study showed an ORR advantage for patients with measurable disease at baseline treated with olaparib versus placebo. ${ }^{35}$ This advantage was apparent for ORR assessed by investigators (OR, 3.52; 95\% Cl, 1.34-10.59) and when assessed by BICR (OR, non-evaluable). This same analysis also showed a PFS benefit for patients treated with olaparib versus placebo with either a complete or partial response to platinum-based chemotherapy at baseline. In addition, the analysis determined PFS2 values which 
Figure 2: Hazard ratios of progression-free survival (assessed by different methods) in four key clinical trials evaluating PARP inhibitors as maintenance therapy for recurrent ovarian carcinoma in differing patient populations

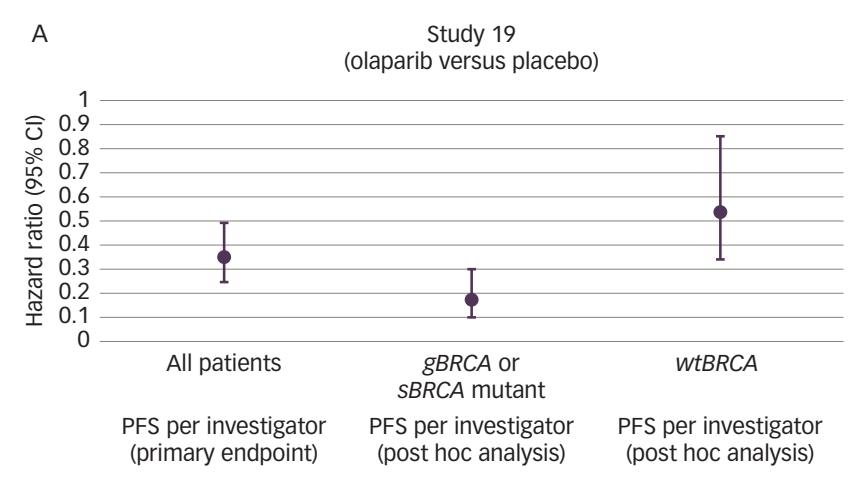

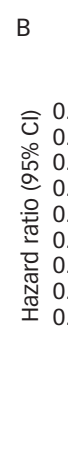

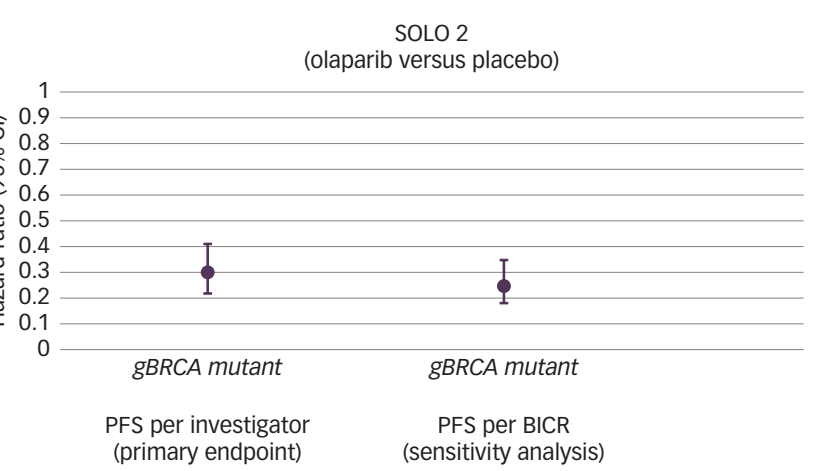

C

NOVA

(niraparib versus placebo)

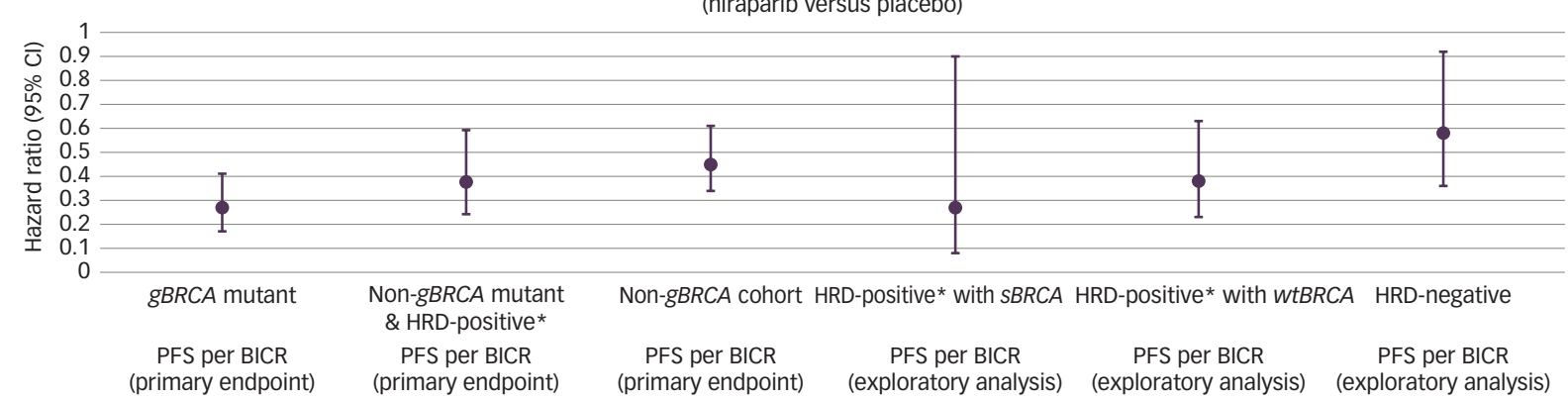

D

ARIEL3

(rucaparib versus placebo)

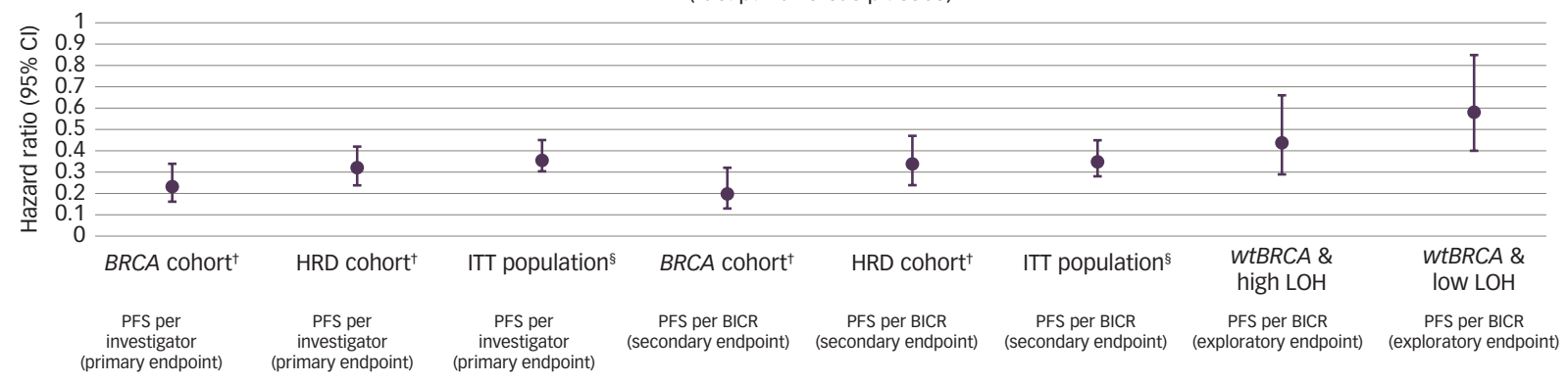

Note that PFS was assessed using different methods in the four studies: SOLO2, Study 19 and ARIEL3 were investigator assessed, whereas NOVA was BICR aSSesSed. The populations in these studies had different mutation profiles and inclusion/exclusion criteria, so the results are not directly comparable.

${ }^{*}$ HRD-positive was defined as having HRD according to the myChoice ${ }^{\circledast}$ HRD test (Myriad Genetics, Salt Lake City, Utah, USA). ${ }^{\dagger}$ Includes patients with a gBRCA or SBRCA mutation. ¥Includes patients with a gBRCA or SBRCA mutation and patients with wtBRCA and high LOH defined as $\geq 16 \%$ genomic LOH per T5 NGS assay (Foundation Medicine, Cambridge, MA, USA). s/ncludes all patients enrolled (gBRCA mutation, SBRCA mutation, wtBRCA and high LOH, wtBRCA and low LOH, wtBRCA and LOH indeterminate).

$\mathrm{BICR}=$ blinded independent central review; $\mathrm{BRCA}=$ breast cancer gene; $\mathrm{Cl}=$ confidence interval; $\mathrm{gBRCA}=$ germline $\mathrm{BRCA} 1$ or $\mathrm{BRCA2} ; \mathrm{HRD}=$ homologous recombination deficiency; ITT = intent-to-treat; $\mathrm{LOH}=$ loss of heterozygosity; NGS = next-generation sequencing; PFS = progression-free survival; sBRCA = somatic BRCA1 or BRCA2; wtBRCA = wild-type BRCA1 or BRCA2.

Source: Plotted from data presented in Pujade-Lauraine et al. 2017, ${ }^{15}$ Ledermann et al. 2012, ${ }^{13}$ Mirza et al. $2016^{10}$ and Coleman et al. 2017. ${ }^{11}$

revealed long-term benefits of olaparib treatment. This benefit was apparent both for patients with a complete response (HR, 0.41; 95\% $\mathrm{Cl}, 0.22-0.77)$ and for patients with a partial response ( $\mathrm{HR}, 0.57 ; 95 \% \mathrm{Cl}$, $0.36-0.91$ ) to platinum-based chemotherapy at study entry.

Most AES were of grade 1-2 severity, and the most common AES of any grade (olaparib versus placebo) were nausea (76\% versus $33 \%$ ), fatigue/asthenia (66\% versus $39 \%$ ), anaemia (44\% versus $8 \%$ ), vomiting (37\% versus 19\%) and diarrhoea (33\% versus 20\%) (Figure $4 A) .{ }^{15}$ More frequent AEs of grade $\geq 3$ included anaemia (19\% versus $2 \%$ ), neutropaenia ( $5 \%$ versus $4 \%$ ) and fatigue/asthenia (4\% versus $2 \%$ ) (Figure $4 A$ ). Discontinuations due to AEs occurred in $11 \%$ of olaparib-treated and $2 \%$ of placebo-treated patients. In SOLO2, four patients (2\%) in the olaparib arm and four patients (4\%) in the placebo arm were reported to have myelodysplastic syndrome or acute myeloid leukaemia. The study showed that the benefits of olaparib on PFS had no detrimental effect on QoL and the toxicities were mostly low grade and manageable. This was emphasised by further analysis of SOLO2 data showing significant improvement in mean quality-adjusted PFS (QA-PFS) for olaparib versus placebo: 14.0 versus 7.3 months (difference, 6.7; 95\% Cl, 5.0-8.5; $\mathrm{p}<0.0001$ ). ${ }^{36}$ In addition, there was also a significant improvement in mean duration of time without symptoms of disease or toxicity (TWiST): 15.0 versus 7.7 months (difference, $7.3 ; 95 \% \mathrm{Cl}, 4.7-9.0 ; p<0.0001$ ). ${ }^{36}$

\section{Niraparib}

In the phase III NOVA trial $(\mathrm{N}=553)$, patients were grouped according to whether they had a gBRCA mutation or a non-gBRCA mutation (this group also included patients with SBRCA mutations) (Table 1). The study also included an analysis that grouped patients by HRD. ${ }^{10} \mathrm{Here}$, the HRDpositive group included patients with SBRCA mutations or other HRD as 
Figure 3: Kaplan-Meier plots of BICR-assessed progression-free survival in patients with BRCA1/2 mutations in A. the SOLO2 (sensitivity analysis), B. the NOVA (primary endpoint) and C. the ARIEL3 (secondary endpoint) trials during maintenance treatment of recurrent ovarian carcinoma

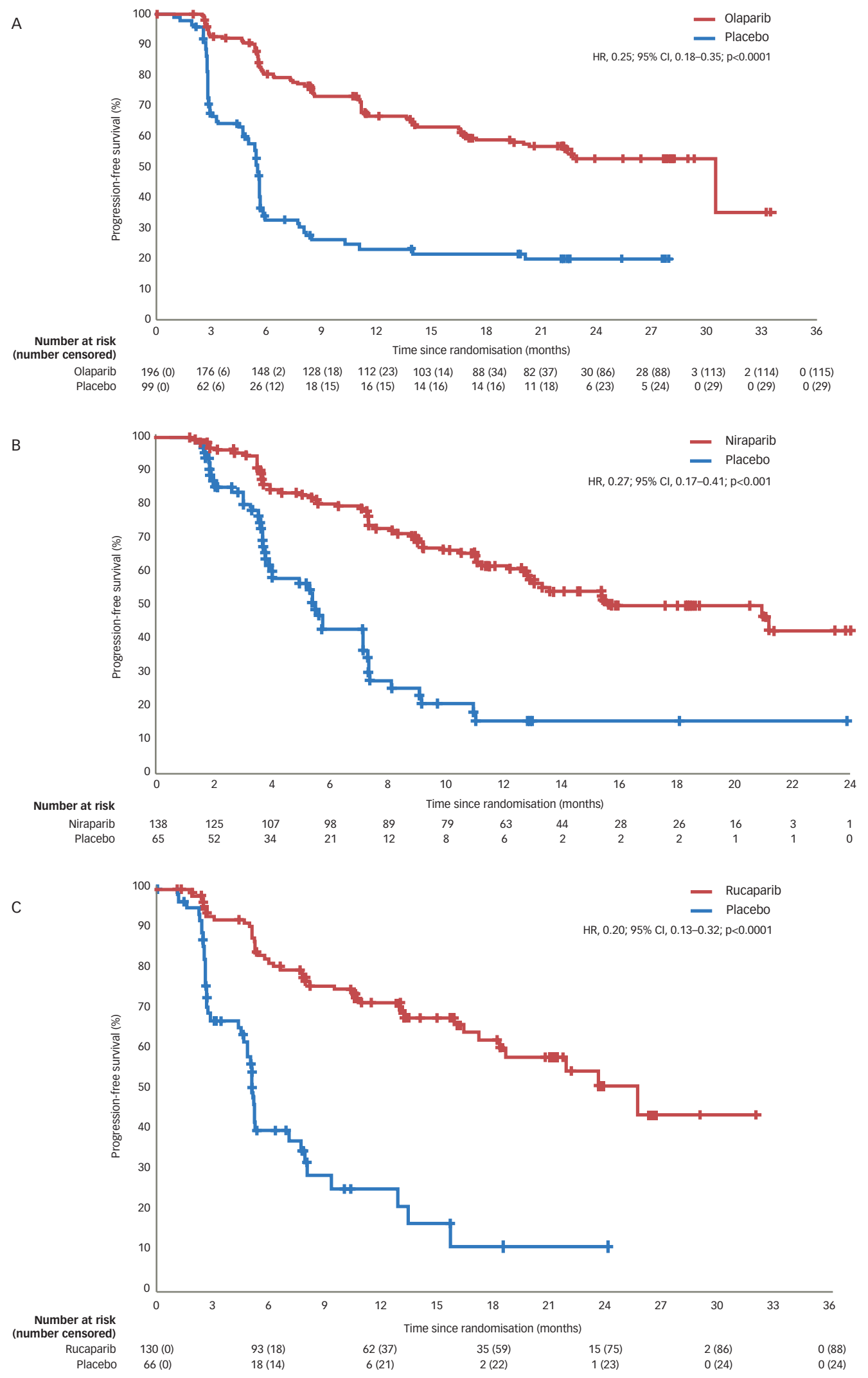

Note that the populations in these studies had differing mutation profiles and inclusion/exclusion criteria differed so the findings are not directly comparable. The data shown in panels A (from SOLO2) and B (from NOVA) include patients with germline BRCA mutations only (no somatic BRCA mutations), while the data shown in panel $C$ from ARIEL3 includes both somatic and germline BRCA mutations.

$B I C R=$ blinded independent central review; $\mathrm{Cl}=$ confidence interval; $H R=$ hazard ratio.

Source: Coleman et al. 2017, 11 Pujade-Lauraine et al. $2017^{15}$ and Mirza et al. 2016 (reproduced with permission). ${ }^{10}$ 
Figure 4: Most frequent ( $\geq 15 \%$ patients in the treatment arm) non-haematological and haematological adverse events reported in the A. SOLO2, B. NOVA and C. ARIEL3 trials during maintenance treatment of recurrent ovarian carcinoma

A

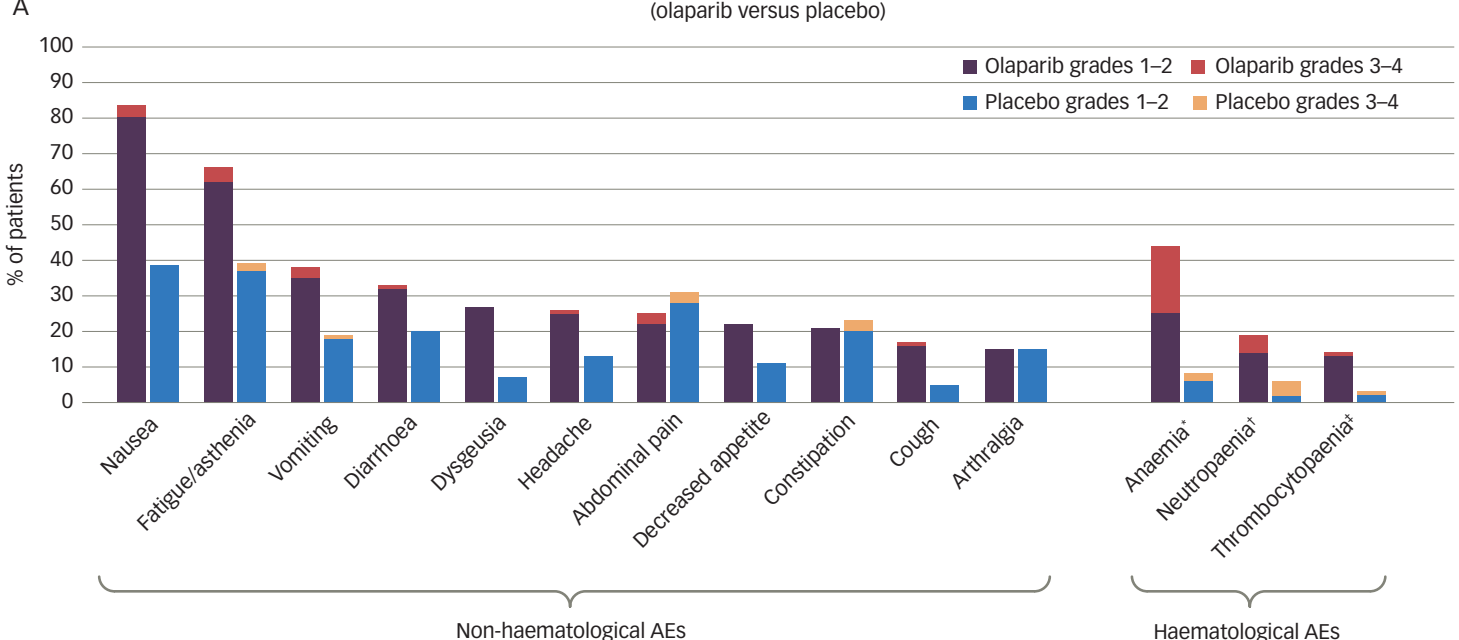

B
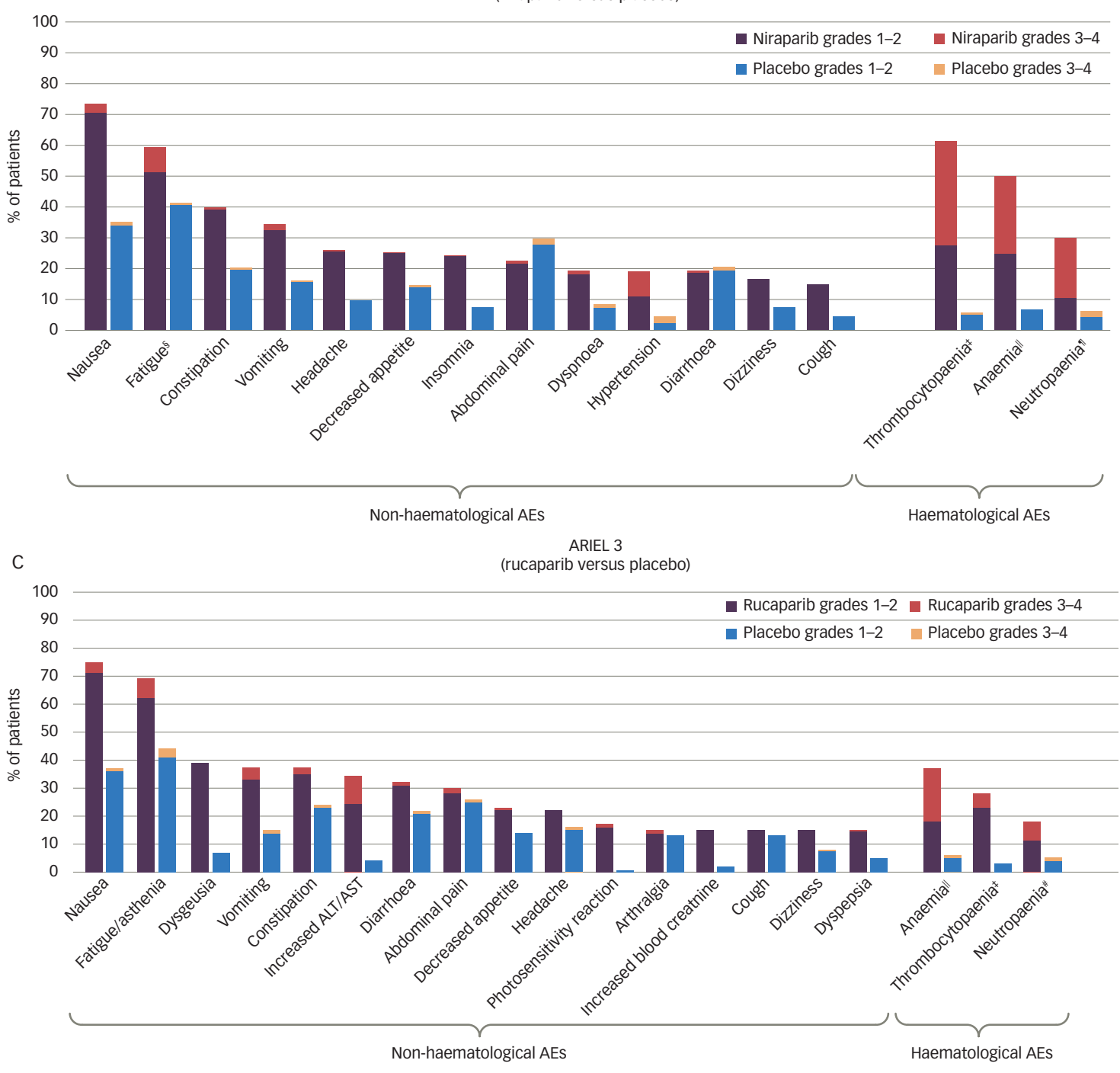

Note that the populations in these studies had differing mutation profiles and inclusion/exclusion criteria differed so the findings are not directly comparable. *Includes anaemia, haemoglobin decreased, haematocrit decreased, and red blood cell count decreased. 'Includes neutropaenia, febrile neutropaenia, neutropaenic sepsis, neutrophil count decreased, granulocytopaenia and granulocyte count decreased. ‡/ncludes thrombocytopaenia and platelet count decreased. §/ncludes fatigue, asthenia, malaise and lethargy. "Includes anaemia and decreased haemog/obin count. "/ncludes neutropaenia, decreased neutrophil count, and febrile neutropaenia. \#Includes neutropaenia and decreased neutrophil count.

$A L T=$ alanine aminotransferase; $A S T=$ aspartate aminotransferase.

Source: Plotted from data in Pujade-Lauraine et al. 2017, ${ }^{15}$ Mirza et al. $2016^{10}$ and Coleman et al. 2017.11 
determined by the mychoice ${ }^{\circledast}$ HRD test (Myriad Genetics, Salt Lake City, Utah, USA). In the gBRCA cohort, BICR-assessed PFS (primary endpoint) for niraparib versus placebo ( $n=138$ and $n=65$, respectively) was 21.0 versus 5.5 months ( $\mathrm{HR}, 0.27 ; 95 \% \mathrm{Cl}, 0.17-0.41 ; \mathrm{p}<0.001$; Figure $2 \mathrm{C}$ and Figure $3 B$ ). In the non-gBRCA/HRD-positive subgroup, PFS for niraparib and placebo, respectively, was 12.9 versus 3.8 months $(\mathrm{HR}, 0.38 ; 95 \% \mathrm{Cl}$, $0.24-0.59 ; \mathrm{p}<0.001$; Figure $2 C$ ). In the overall non-gBRCA cohort, median PFS was 9.3 versus 3.9 months ( $\mathrm{HR}, 0.45$; $95 \% \mathrm{Cl}, 0.34-0.61 ; \mathrm{p}<0.001$; Figure $2 C$ ). An analysis of BICR-assessed PFS in subgroups based on HRD status indicated that niraparib treatment was superior to placebo across all subgroups (Figure 2C): non-gBRCA/HRD-positive/SBRCA ( $n=35$ and $n=12$, respectively): 20.9 versus 11.0 months (HR, 0.27; 95\% $\mathrm{Cl}$, 0.08-0.90; $\mathrm{p}=0.02$ ); non-gBRCA/HRD-positive/wtBRCA ( $\mathrm{n}=71$ and $\mathrm{n}=44$ ): 9.3 versus 3.7 months ( $\mathrm{HR}, 0.38 ; 95 \% \mathrm{Cl}, 0.23-0.63$; $\mathrm{p}<0.001$ ); non-gBRCA/HRD-negative ( $n=92$ and $n=42): 6.9$ versus 3.8 months ( $H R$, 0.58; 95\% Cl, 0.36-0.92; $\mathrm{p}=0.02)$. ${ }^{10,37}$ Data for secondary endpoints of chemotherapy-free interval (CFI), TFST, PFS2 and OS were subsequently reported. 38,39 In the gBRCA cohort, niraparib significantly improved median CFI (22.8 months) compared to placebo (9.4 months; HR, 0.26; $95 \% \mathrm{Cl}, 0.17-0.41)$. Median CFI was also improved in the non-gBRCA cohort (12.7 months versus 8.6 months; HR, 0.50; 95\% Cl, 0.37-0.67). Median TFST was significantly improved versus placebo for the gBRCA (21.0 months versus 8.4 months; HR, 0.31 ; $95 \% \mathrm{Cl}, 0.21-0.48$ ) and nongBRCA (11.8 months versus 7.2 months; HR, 0.55; 95\% Cl, 0.41-0.72) cohorts. Though data were immature (gBRCA, 30\%; non-gBRCA, 50\%), PFS2 was longer with niraparib than placebo (gBRCA: $\mathrm{HR}, 0.48 ; 95 \% \mathrm{Cl}$, 0.24-0.69; non-gBRCA: HR, 0.69; $95 \% \mathrm{Cl}, 0.49-0.96)$. Less than $20 \%$ of OS events had occurred in the overall patient population, but analysis showed a non-significant improvement with niraparib versus placebo ( $\mathrm{HR}, 0.73$; 95\% Cl, 0.48-1.13). ${ }^{38,39}$

In the NOVA trial, the most frequent AEs of any grade with niraparib versus placebo were nausea (74\% versus 35\%), thrombocytopaenia (61\% versus 6\%), fatigue/asthenia (59\% versus $41 \%)$, anaemia $(50 \%$ versus $7 \%$ ), constipation (40\% versus $20 \%$ ), vomiting (34\% versus $16 \%$ ) and neutropaenia (30\% versus 6\%) (Figure $4 B$ ). The most common grade $\geq 3 \mathrm{AES}$ with niraparib versus placebo were thrombocytopaenia (34\% versus $1 \%$ ), anaemia ( $25 \%$ versus $0 \%$ ), neutropaenia (20\% versus $2 \%$ ), fatigue/asthenia (8\% versus $1 \%$ ) and hypertension (8\% versus $2 \%$ ) (Figure $4 B$ ). These were managed by modifying or delaying the niraparib dose. With niraparib, $15 \%$ of patients discontinued treatment due to an AE compared with $2 \%$ with placebo. Myelodysplastic syndrome or acute myeloid leukaemia were reported by five patients (1\%) in the niraparib arm and two (1\%) in the placebo arm..$^{10}$

In an analysis of QoL for patients in NOVA, mean pre-progression EQ$5 \mathrm{D}-5 \mathrm{~L}$ scores were similar between the niraparib and placebo arms in both the gBRCA (0.838 versus 0.834) and non-gBRCA (0.833 versus $0.815)$ cohorts. $^{40}$ At baseline, common symptoms related to QoL included fatigue, pain, nausea, vomiting, bloating and cramps as assessed by the FOSI questionnaire. These symptoms generally remained stable or improved for patients in the niraparib arm, with the exception of nausea which showed an increase at cycle 2 but declined towards baseline levels thereafter. ${ }^{40} \mathrm{~A}$ more recent analysis of NOVA study data found that mean TWiST for patients receiving niraparib was 2.95 years for patients with gBRCA mutations compared with 1.34 years for patients without gBRCA mutations. ${ }^{41,42}$ Niraparib treatment of these patient groups produced PFS benefits of 3.23 years and 1.44 years, respectively, and mean toxicity times of 0.28 years and 0.11 years, respectively. QoL remained stable through niraparib treatment and the pre-progression period compared with placebo.

\section{Rucaparib}

ARIEL3 was a randomised phase III trial (intent-to-treat [ITT] population, $\mathrm{N}=564$ ) to assess the efficacy and safety of rucaparib as maintenance treatment (600 mg BID, $n=375)$ versus placebo ( $n=189) .{ }^{11}$ Patients with high-grade, platinum-sensitive ovarian carcinoma were required to have shown an objective response to second-line or later platinum-based chemotherapy. A novel aspect of this trial was the prospective validation of the next-generation sequencing assay performed in collaboration with Foundation Medicine (Cambridge, Massachusetts, USA) to identify tumours with high genomic LOH. In ARIEL3, a cut-off of $\geq 16 \%$ for high $\mathrm{LOH}$ was prospectively selected based on the results of a planned post hoc analysis of data from a prior phase II study, ARIEL $2 .{ }^{16}$ In the analysis of ARIEL2 data, a cut-off of $\geq 16 \%$ improved median PFS in the LOH-high subgroup compared to the prespecified $\geq 14 \%$ cut-off ( 7.2 months versus 5.7 months). The HR for PFS was also improved with the $\geq 16 \%$ cut-off $(0.51$ [95\% $\mathrm{Cl}, 0.34-0.74]$ versus 0.62 [95\% $\mathrm{Cl}, 0.42-0.90]){ }^{16}$

The design of the ARIEL3 study involved a prospectively defined stepdown statistical procedure of three nested cohorts. ${ }^{11}$ Firstly, the BRCAmutant cohort $(n=196)$ consisted of 130 patients with gBRCA mutations ( $n=82$ and $n=48$ for rucaparib and placebo, respectively), 56 patients with SBRCA mutations ( $\mathrm{n}=40$ and $\mathrm{n}=16$ ) and 10 patients with unknown $g B R C A$ or $S B R C A$ status ( $n=8$ and $n=2)$. Secondly, the HRD cohort $(n=354)$ included the BRCA-mutant cohort and a further 158 patients with wtBRCA and high LOH ( $n=106$ and $n=52$ ). Thirdly, the ITT population $(n=564)$ consisted of the HRD cohort with an additional 161 patients with wtBRCA and low $\mathrm{LOH}(\mathrm{n}=107$ and $\mathrm{n}=54)$ and 49 patients with wtBRCA and indeterminate $\mathrm{LOH}(\mathrm{n}=32$ and $n=17)$.

The primary endpoint of ARIEL3 (investigator-assessed PFS) showed a significant benefit for rucaparib in each of the three cohorts. The median PFS in patients with BRCA-mutant carcinoma was 16.6 months for rucaparib versus 5.4 months for placebo $(\mathrm{HR}, 0.23$; $95 \% \mathrm{Cl}, 0.16-0.34$; $\mathrm{p}<0.0001$; Figure 2D). Median investigator-assessed PFS also showed significant advantages for rucaparib over placebo in patients with HRD carcinoma: 13.6 months for rucaparib versus 5.4 months for placebo ( $\mathrm{HR}, 0.32 ; 95 \% \mathrm{Cl}, 0.24-0.42 ; \mathrm{p}<0.0001)$. In the ITT population, investigatorassessed PFS was 10.8 months for rucaparib and 5.4 months for placebo (HR, 0.36; 95\% Cl, 0.30-0.45; $\mathrm{p}<0.0001$ ). Median BICR-assessed PFS for patients with BRCA-mutant carcinoma was 26.8 months for rucaparib versus 5.4 months for placebo ( $\mathrm{HR}, 0.20 ; 95 \% \mathrm{Cl}, 0.13-0.32$; $\mathrm{p}<0.0001$; Figure $3 C$ ); for patients with HRD, it was 22.9 months versus 5.5 months ( $\mathrm{HR}, 0.34 ; 95 \% \mathrm{Cl}, 0.24-0.47 ; \mathrm{p}<0.0001$ ) and for all patients in the ITT population, it was 13.7 months versus 5.4 months (HR, 0.35 ; $95 \% \mathrm{Cl}$, 0.28-0.45; $p<0.0001$; Figure 2D). ${ }^{11}$ Pre-planned subgroup analyses found that rucaparib provided a PFS benefit in all clinical subgroups compared with placebo regardless of time to progression on penultimate platinumbased treatment, response to last platinum-based treatment, having a bulky lesion $(>2 \mathrm{~cm}$ ) at baseline and having measurable disease at baseline."1 Investigator-assessed PFS was also significantly longer with rucaparib compared with placebo in patients with wtBRCA/LOH-high carcinomas (median 9.7 months versus 5.4 months, respectively; HR, $0.44 ; 95 \% \mathrm{Cl}, 0.29-0.66 ; \mathrm{p}<0.0001$ ) and in patients with wtBRCA/LOH-low carcinomas (median 6.7 months versus 5.4 months, respectively; HR, 0.58; $95 \% \mathrm{Cl}, 0.40-0.85 ; \mathrm{p}=0.0049$; Figure 2D). OS data from the ARIEL3 study are currently immature. ${ }^{11}$

An exploratory analysis of investigator-assessed ORR in patients with measurable disease showed superiority for rucaparib over placebo for all three cohorts in ARIEL 3 (Table 2). These included significant $(p<0.05)$ improvements over placebo for measures of ORR evaluated by 
Table 2: Exploratory analysis of investigator-assessed objective response rate for patients with measurable disease at baseline in the ARIEL3 study

\begin{tabular}{|c|c|c|c|c|c|c|}
\hline & \multicolumn{2}{|c|}{ BRCA Mutant } & \multicolumn{2}{|l|}{ HRD } & \multicolumn{2}{|l|}{$\mathrm{ITT}$} \\
\hline & $\begin{array}{l}\text { Rucaparib } \\
(n=40)\end{array}$ & $\begin{array}{l}\text { Placebo } \\
(n=23)\end{array}$ & $\begin{array}{l}\text { Rucaparib } \\
(\mathrm{n}=85)\end{array}$ & $\begin{array}{l}\text { Placebo } \\
(n=41)\end{array}$ & $\begin{array}{l}\text { Rucaparib } \\
(\mathrm{n}=141)\end{array}$ & $\begin{array}{l}\text { Placebo } \\
(\mathrm{n}=66)\end{array}$ \\
\hline Complete response & $17.5(7)$ & $0(0)$ & $11.8(10)$ & $0(0)$ & $7.1(10)$ & $1.5(1)$ \\
\hline Partial response & $20.0(8)$ & $8.7(2)$ & $15.3(13)$ & $7.3(3)$ & $11.3(16)$ & $6.1(4)$ \\
\hline Progressive disease & $12.5(5)$ & $56.5(13)$ & $21.2(18)$ & $51.2(21)$ & $27.0(38)$ & 48.5 (32) \\
\hline Not evaluable & $2.5(1)$ & $0(0)$ & $1.2(1)$ & $0(0)$ & $4.3(6)$ & $0(0)$ \\
\hline
\end{tabular}

*Cochrane-Mantel-Haenszel $p<0.05$ versus placebo.

$H R D=$ homozygous recombination deficiency; ITT = intent-to-treat; ORR = objective response rate; $R E C I S T=$ Response Evaluation Criteria in Solid Tumours

Source: Coleman et al. 2017 (supplementary material). ${ }^{11}$

RECIST. Among rucaparib-treated patients, there were also substantial improvements over placebo in terms of conversion from a partial to a complete response. ${ }^{11}$

In ARIEL3, the most common treatment-emergent AES of any grade (rucaparib versus placebo) were nausea (75\% versus 37\%), fatigue/ asthenia (69\% versus $44 \%$ ), dysgeusia (39\% versus $7 \%$ ), anaemia (37\% versus 6\%), constipation (37\% versus $24 \%$ ), vomiting (37\% versus $15 \%)$, increased alanine or aspartate aminotransferase concentration (ALT/AST) (34\% versus 4\%) and diarrhoea (32\% versus 22\%) (Figure 4C). Treatment-emergent AEs of grade $\geq 3$ were reported in $56 \%$ of patients in the rucaparib group versus $15 \%$ in the placebo group. The most notable and frequent of these were anaemia (19\% versus 1\%), increased ALT/ AST (10\% versus $0 \%$ ), fatigue/asthenia (7\% versus $3 \%)$, neutropaenia (7\% versus $2 \%$ ), thrombocytopaenia ( $5 \%$ versus $0 \%$ ) and nausea $(4 \%$ versus 1\%) (Figure 4C). ${ }^{11}$ Discontinuations due to an AE (excluding disease progression) occurred in $13 \%$ and $2 \%$ of patients, respectively. Myelodysplastic syndrome or acute myeloid leukaemia were reported in three patients (1\%) receiving rucaparib, of these, two had gBRCAmutant carcinoma and one had wtBRCA/LOH-low carcinoma, and no patients in the placebo arm. Overall, the safety findings showed that rucaparib was well tolerated and AEs were manageable; they were mainly low grade and the incidence of more serious events declined after initial cycles of treatment.

In an analysis of the secondary endpoint of time to worsening on the disease-related symptoms-physical subscale of the FOSI-18 questionnaire, no significant difference was noted between the rucaparib and placebo arms in the BRCA-mutant cohort (HR, 1.24; 95\% $\mathrm{Cl}, 0.82-1.86) .{ }^{11}$ An analysis of patient-centred outcomes in the ARIEL3 study has recently reported that mean QA-PFS was significantly longer for patients treated with rucaparib compared with placebo (12.02 versus 5.74 months) and that in patients with wtBRCA, mean QA-PFS was longer for rucaparib than placebo regardless of LOH status. ${ }^{43}$ Mean quality-adjusted TWiST analysed using all grade $\geq 3$ treatment-emergent AEs was significantly longer for rucaparib than placebo (ITT population, 13.32 versus 6.44 months) and for patients with a BRCA mutation (16.42 versus 6.68 months, respectively). Additional patient-reported outcomes data are expected to be published in the future.

\section{Discussion}

For women with platinum-sensitive ovarian cancer, PARP inhibitor maintenance treatment constitutes a new standard of care that can delay the need for further chemotherapy. In key clinical trials, olaparib, niraparib and rucaparib maintenance treatment notably increased PFS for patients with recurrent ovarian cancer following a response to second- or later-line platinum-based chemotherapy. ${ }^{10,11,13,15}$ As might be expected, in these trials, PARP inhibitors were effective in patients with recurrent ovarian cancer and BRCA mutations. In non-gBRCA patients enrolled in NOVA and in patients with wtBRCA in ARIEL3, niraparib and rucaparib, respectively, were also effective in patients with HRD. 10,11 However, while both of these studies found that PFS was improved in patients with tumours associated with HRD, there are distinct differences in the methods used to classify patients with HRD. In NOVA, the HRD status of tumours was evaluated using the mychoice HRD test and the HRD-positive group in the primary analysis included patients with an SBRCA mutation. ${ }^{10}$ An exploratory analysis in NOVA did show a benefit for patients with wtBRCA and HRD (SBRCA not included). ARIEL3 examined $\mathrm{LOH}$ as a biomarker for HRD, and in an exploratory analysis of patients with wtBRCA and high LOH, PFS was improved with rucaparib versus placebo. ${ }^{11}$ Furthermore, in both studies, patients without a BRCA mutation or HRD demonstrated improvement in PFS, indicating that neither $B R C A$ status nor HRD is a sufficiently precise biomarker to predict which patients will benefit from PARP inhibitor maintenance treatment. ${ }^{10,11}$ The FDA and European approvals for olaparib, niraparib and rucaparib use as second-line maintenance therapy of recurrent ovarian cancer do not specify BRCA mutation type or HRD status. ${ }^{25-27}$

The studies described here also demonstrated the benefits of PARP inhibitor maintenance treatment in addition to extension of PFS. In ARIEL3, rucaparib treatment led to a higher ORR than placebo with a number of patients with a partial response converting to a complete response on study. ${ }^{11}$ In SOLO2, there were also notable advantages in ORR for olaparib compared with placebo in patients with measurable disease at baseline. ${ }^{35}$ Thus in some patients not only is progression delayed, or even prevented, they may have a deepening of response following maintenance therapy with a PARP inhibitor. Study 19, SOLO2, NOVA and ARIEL3 assessed secondary and exploratory endpoints, including CFI, TFST, PFS2 and TSST (first used in Study 19 as exploratory endpoints). 15,38,39,44,45 PARP inhibitor maintenance treatment was associated with improvements in these endpoints, providing further evidence that these drugs are suitable for maintenance therapy in which the objective is to delay the need for additional therapy. Furthermore, the results also suggest that PARP inhibitor treatment does not affect the efficacy of subsequent lines of treatment. 15,38,39 For OS, an analysis of all patients in Study 19 showed that olaparib maintenance treatment resulted in a small but non-significant improvement over placebo (29.8 months versus 27.8 months, respectively), with the largest improvement observed in patients 
with a BRCA mutation (34.9 months versus 30.2 months, respectively). ${ }^{45} \mathrm{~A}$ notable minority of patients in this study appear to be long-term survivors with $11 \%$ receiving olaparib treatment for $>6$ years. OS data for the phase III studies are currently immature. 10,11,15

The safety and tolerability findings in the pivotal maintenance studies indicate that olaparib, niraparib and rucaparib have somewhat similar AE profiles. 10,11,13,15 Many AEs appear to be class effects of PARP inhibitors, such as haematological AEs (e.g., anaemia, thrombocytopaenia, neutropaenia), gastrointestinal AEs (e.g., nausea, vomiting) and fatigue/asthenia. In general, the majority of AEs were low grade and/or transient and were managed with treatment interruption, dose reductions and/or supportive care (e.g., transfusions, antiemetic medications). Discontinuation rates associated with AEs were also similar across trials and were generally higher in the PARP inhibitor arms than in the placebo groups. 10,11,13,15

Notable differences in the AE profiles include a higher incidence of any grade and grade $\geq 3$ haematological AEs, particularly thrombocytopaenia, with niraparib compared with olaparib and rucaparib. An exploratory analysis of the NOVA trial (RADAR) identified two significant parameters that could be used to predict the need for niraparib dose modification. ${ }^{46,47}$ These were a baseline body weight of $<77 \mathrm{~kg}$ and/or baseline platelet counts of $<150,000 / \mu \mathrm{l}$. It is critical that these criteria be monitored and the dose of niraparib adjusted to improve tolerability. In response to these findings, a protocol amendment was made in the ongoing PRIMA study which permitted starting dose reductions in patients with low body weight or platelet counts. ${ }^{48}$ This dose modification has recently been reported to be associated with a significant decrease in grade $\geq 3$ haematological and non-haematological toxicities and an approximately $80 \%$ reduction in grade 4 thrombocytopaenia and platelet transfusions. ${ }^{49}$ With olaparib, niraparib and rucaparib it is necessary to monitor full blood counts at baseline and during subsequent treatment due to the reported incidence of myelosuppression and thrombocytopaenia. ${ }^{23,25-27}$ Hypertension (any grade and grade $\geq 3$ ) was also observed more frequently with niraparib than with olaparib and rucaparib. Niraparib's effect on hypertension is believed to be linked to its pharmacological inhibition of the dopamine transporter, norepinephrine transporter and serotonin transporter.50 Niraparib requires monthly monitoring for hypertension during the first year and periodically thereafter during treatment. ${ }^{25,50}$ With rucaparib, the incidence of any grade elevations in AST/ALT was higher than reported with olaparib or niraparib. These increases were transient and not associated with criteria for drug-induced hepatotoxicity. ${ }^{11}$ Some of the other differences in the AEs observed may be reflective of the specific PARP enzymes that each drug can target; all three inhibit PARP1 and PARP2 but their actions against other PARPS are variable. ${ }^{23,51,52}$ Olaparib, niraparib and rucaparib have been reported to increase levels of serum creatinine..$^{25-2,53}$ This is believed to be a PARP inhibitor class effect resulting from inhibition of creatinine transporters in the kidney but not a result of acute kidney injury. ${ }^{23,54,55}$ The exact consequences of the variable toxicity of the PARP inhibitors have not been entirely elucidated and may warrant further investigation.

Based on available data from Study 19, SOLO2, NOVA and ARIEL3, maintenance treatment with a PARP inhibitor did not have a detrimental impact on QoL for patients with recurrent ovarian cancer. ${ }^{11,32,3,40}$ Evaluations of data from SOLO2 and ARIEL3 even demonstrated that olaparib and rucaparib maintenance treatment resulted in a longer period in which patients did not experience disease symptoms or toxicity compared to patients receiving placebo, emphasising another advantage of PARP inhibitor maintenance therapy for patients with recurrent ovarian cancer. ${ }^{36,43}$ The pivotal studies have demonstrated the utility of PARP inhibition as maintenance treatment following second-line or later platinum-based chemotherapy. In the future, it will be of interest to determine if these, or other PARP inhibitors, could be effectively used earlier in ovarian carcinoma maintenance treatment. The recent SOLO1 phase III study $(n=391)$ investigated the use of olaparib as first-line maintenance treatment in patients with newly diagnosed advanced ovarian carcinoma and germline $(\mathrm{n}=388)$ or somatic $(\mathrm{n}=2)$ BRCA1/2 mutations. ${ }^{56,57}$ The results showed clinically significant benefits of PARP inhibitor maintenance treatment versus placebo after a median 41 months of follow-up. ${ }^{57}$ The risk of disease progression or death was $70 \%$ lower with olaparib than with placebo. The AE profile was consistent with the known toxic effects of olaparib. These results indicate the potential of PARP inhibitors as first-line maintenance therapy. A similar phase III randomised study, PRIMA ( $n=630),{ }^{48}$ in which niraparib is being assessed versus placebo as maintenance treatment for stage III or IV ovarian cancer in patients who showed a response to front-line platinum-based chemotherapy, has completed recruitment and the efficacy results are awaited.

\section{Future directions}

As use of PARP inhibitors increases and indications expand to allow earlier use, their roles in the treatment of ovarian cancer and sequencing of use relative to other anticancer agents will need to be evaluated. Cross-resistance between PARP inhibitors might be circumvented due to the different PARP enzymes targeted by these therapies, suggesting that a 'PARP-after-PARP' strategy may be suitable for patients who have not responded to one of these drugs or has initially responded but then progressed. ${ }^{58,59}$ This strategy could involve patients who have either stopped PARP treatment after progression or who have stopped after a defined period, for example, following first-line therapy, without progression. One approach that is being investigated in the OReO study (ClinicalTrials.gov identifier: NCT03106987, $n=416$ ) is that patients with ovarian carcinoma who originally responded to platinum-based chemotherapy and subsequently progressed on a PARP inhibitor are then switched to olaparib treatment. Patients recruited to this study will have received different previous treatments. Many, for example, will have originally received olaparib and are re-treated with the same drug after further platinum-based chemotherapy. As PARP inhibitors are being introduced earlier in the pathway of treatment, research strategies are needed to explore the effects of re-treatment at a later date. Sequencing in relation to other widely used treatments for ovarian cancer will also require examination as most available data currently comes from trials performed in the second line or later.

The utility of PARP inhibitors in the maintenance setting for recurrent ovarian cancer may be improved by combining them with other agents that have different mechanisms of action, such as those that interfere with DNA replication and repair pathways (e.g., ATR, ATM, CHK1/2 and WEE1). ${ }^{60,61}$ For example, antiangiogenic agents (e.g., bevacizumab) induce chronic hypoxia in tumours, which induces a down-regulation of BRCA1 and RAD51, leading to HRD, although this effect is controversial. ${ }^{62}$ Thus tumours with hypoxia-induced HRD may be sensitive to PARP inhibition. This effect was also shown in a recent study using mouse tumour xenografts, in which cediranib treatment resulted in sensitivity to olaparib by producing hypoxia which suppresses the expression of the HRD factors BRCA1/2 and RAD51 recombinase. ${ }^{63,64}$ However, cediranib also had a direct effect on HRD, independent of its ability to induce tumour hypoxia. This effect was specific to tumour cells and suggested that DNA repair could be manipulated to induce synergistic lethality.

Combination with checkpoint inhibitors (e.g., nivolumab [anti-programmed cell death protein 1 [PD-1\}]) is another strategy as tumours with HRD 
express high levels of novel, tumour-specific protein sequences, which can attract programmed death-ligand 1 (PD-L1)-expressing tumour-infiltrating lymphocytes. ${ }^{65}$ Preclinical studies have shown that rucaparib combined with an anti-PD-1 inhibitor improved antitumour activity in a BRCA-deficient mouse model. ${ }^{66}$ Several studies of PARP inhibitors in combination with other agents in patients with ovarian cancer are currently being conducted or are nearing completion. These include PAOLA-1 (ClinicalTrials.gov identifier: NCT02477644, a randomised controlled phase III trial - maintenance olaparib with bevacizumab), OVARIO (NCT03326193, a randomised phase II trial - maintenance niraparib with bevacizumab), ATHENA (NCT03522246, a randomised phase III trial - maintenance rucaparib with nivolumab). ${ }^{67-69}$ There is also the ongoing VELIA study (NCT02470585, a phase III trial in previously untreated advanced ovarian cancer, randomised to one of three regimens: carboplatin/paclitaxel plus veliparib then veliparib maintenance or carboplatin/paclitaxel plus placebo then placebo maintenance or carboplatin/paclitaxel plus veliparib then placebo maintenance).

An open-label trial involving PARP inhibitors in combination with other treatments for ovarian cancer, the JAVELIN OVARIAN PARP 100 (NCT03642132, avelumab with chemotherapy then maintenance with avelumab and talazoparib), was recently terminated due to futility after another similar study, the JAVELIN OVARIAN 100, failed to meet its primary endpoint. ${ }^{70} \mathrm{~A}$ further open-label trial is the ongoing phase III FIRST study (NCT03602859), in which patients are treated with first-line platinumbased chemotherapy with TSR-042 (dostarlimab, anti-PD-1 monoclonal antibody) and niraparib.

An alternative combination approach is being taken in the ongoing ENGOT-OV46/AGO/DUO-O trial (NCT03737643, planned $n=927$ ). This is a phase III randomised, placebo-controlled study in which patients with newly diagnosed advanced ovarian cancer will all initially receive durvalumab in combination with chemotherapy and bevacizumab. This will be followed by randomisation to maintenance durvalumab and bevacizumab or maintenance durvalumab, bevacizumab and olaparib; PFS will be the primary endpoint. An additional study of interest is the ENGOT-OV43/BGOG trial (NCT03740165, planned $n=1,000$ ) in which patients with ovarian cancer will initially receive a single 3-week cycle of carboplatin/paclitaxel. Subsequently, they will be randomised to pembrolizumab and olaparib, pembrolizumab and placebo or placebo alone, with PFS and OS as the primary endpoints.
Beyond ovarian cancer, the PARP inhibitors have also shown encouraging efficacy in the treatment of a variety of other cancers and are being developed as potential treatments in multiple indications, including haematological malignancies, advanced prostate cancer, pancreatic cancer, bladder cancer, triple-negative breast cancer, squamous cell lung cancer, non-small cell lung cancer, colorectal cancer and metastatic melanoma. ${ }^{71-81}$ The use of these drugs as maintenance therapy, however, has mostly focused on recurrent ovarian cancer. Future wider use of the PARP inhibitors as maintenance therapy has the exciting potential to delay progression in many other cancer types.

\section{Conclusion}

Overall, the use of PARP inhibitors as maintenance therapy is an important development in delaying disease progression in recurrent ovarian cancer, and in Study 19 with the longest follow-up, about 10\% of patients have had a sustained response lasting $>6$ years. The findings from these studies justify further investigation of these agents for use as either monotherapy or in combination with other treatments. The PARP inhibitors have differing properties that could be used to provide increased or more suitable treatment options for numerous patients. Greater awareness of these drugs and wider routine application of them in recurrent ovarian cancer maintenance regimens in the future could improve the prognosis and reduce mortality in this continuingly prevalent and lethal disease in women both with and without BRCA mutations.

\section{Study name definitions}

ARIEL3 = Rucaparib maintenance treatment for recurrent ovarian carcinoma after response to platinum-based therapy; NOVA = A trial of niraparib for ovarian cancer that has come back after platinumbased chemotherapy; OReO = Study to examine Olaparib maintenance Retreatment in patients with Epithelial Ovarian cancer; RADAR = Rapid Adjustment of Dose to reduce Adverse Reactions; SOLO1 = Olaparib maintenance monotherapy in patients with BRCA-mutated ovarian cancer following first-line platinum-based chemotherapy; SOLO2 = Olaparib treatment in BRCA-mutated ovarian cancer patients after complete or partial response to platinum-based chemotherapy; Study 19 = a randomised, double-blind placebo-controlled phase II study comparing outcomes with olaparib as maintenance therapy in patients with platinum-sensitive, recurrent high-grade serous ovarian cancer. $\square$
1. World Ovarian Cancer Coalition, The World Ovarian Cancer Coalition Atlas - Global Trends in incidence, mortality and survival, 2018. Available at: https://worldovariancancercoalition. org/wp-content/uploads/2018/10/THE-WORLD-OVARIANCANCER-COALITION-ATLAS-2018.pdf (accessed 20 June 2019).

2. US National Institutes of Health, SEER Cancer Statistics Review 1975-2014 2015. Available at: https://seer.cancergov/archive/ crr/1975_2014/results_merged/sect_21_ovary.pdf (accessed 17 December 2018)

3. American Cancer Society, Key statistics for ovarian cancer, 2019. Available at: www.cancer.org/cancer/ovarian-cancer/ about/key-statistics.html (accessed 7 March 2019).

about/key-statistics.html (accessed 7 March 2019). SEER Cancer Statistic Review 1975-2001-2015, 2018. Available at: https://seer.cancer.gov/archive/csr/1975_2001/results merged/sect_20_ovary.pdf (accessed 17 December 2018).

5. Polyak K, Garber J. Targeting the missing links for cancer therapy. Nat Med. 2011;17:283-4.

6. Farmer $\mathrm{H}, \mathrm{McC}$ abe N, Lord $\mathrm{CJ}$, et al. Targeting the DNA repair defect in BRCA mutant cells as a therapeutic strategy. Nature. 2005; $434: 917-21$

7. Javle M, Curtin NJ. The role of PARP in DNA repair and its therapeutic exploitation Br J Cancer 2011:105:1114-22.

8. Murray I Thomas $\mathrm{H}$ Berny $\mathrm{P}$ et al. Tumour cell retention of rucaparib, sustained PARP inhibition and efficacy of weekly as well as daily schedules. Br I Cancer. 2014;110:1977-84.

well as daily schedules. Br J Cancer. 2014;110:1977-8
Ledermann JA, Drew Y, Kristeleit RS. Homologous

recombination deficiency and ovarian cancer. Eur J Cancer. recombination

10. Mirza MR, Monk BJ, Herrstedt J, et al. Niraparib maintenance therapy in platinum-sensitive, recurrent ovarian cancer. N Engl J Med. 2016;375:2154-64.
11. Coleman RL, Oza AM, Lorusso D, et al. Rucaparib maintenance treatment for recurrent ovarian carcinoma after response to platinum therapy (ARIEL3): a randomised, double-blind, placebo-controlled, phase 3 trial. Lancet. 2017;390:1949-61

12. Swisher EM, Lin KK, Oza AM, et al. Rucaparib in relapsed, platinum-sensitive high-grade ovarian carcinoma (ARIEL2 Part 1): an international, multicentre, open-label, phase 2 trial. Part 1): an international, multicen

13. Ledermann J, Harter P, Gourley C, et al. Olaparib maintenance therapy in platinum-sensitive relapsed ovarian cancer. N Engl. therapy in platinum-sensitive
Med. 2012;366:1382-92.

14. Ledermann J, Harter P, Gourley C, et al. Olaparib maintenance therapy in patients with platinum-sensitive relapsed serous ovarian cancer: a preplanned retrospective analysis of outcomes by BRCA status in a randomised phase 2 trial. Lancet Oncol. 2014;15:852-61.

15. Pujade-Lauraine E, Ledermann JA, Selle F, et al. Olaparib tablets as maintenance therapy in patients with platinum-sensitive, relapsed ovarian cancer and a BRCA1/2 mutation (SOLO2/ ENGOT-Ov21): a double-blind, randomised, placebo-controlled, phase 3 trial. Lancet Oncol. 2017;18:1274-84.

16. Coleman RL, Swisher EM, Oza AM, et al. Refinement of prespecified cutoff for genomic loss of heterozygosity (LOH) prespecifled cutoff for genomic loss of heterozygosity (LOH) in ARIEL2 part 1: a phase II study of rucaparib in patients (pts) with high grade ovarir

17. Sandhu SK, Schelman WR, Wilding G, et al. The poly(ADP-ribose) polymerase inhibitor niraparib (MK4827) in BRCA mutation carriers and patients with sporadic cancer: a phase 1 doseescalation trial. Lancet Oncol. 2013;14:882-92

18. Domchek SM, Aghajanian C, Shapira-Frommer R, et al. Efficacy and safety of olaparib monotherapy in germline BRCA1/2 mutation carriers with advanced ovarian cancer and three or more lines of prior therapy. Gynecol Oncol. 2016;140:199-203.

19. Kaufman B, Shapira-Frommer R, Schmutzler RK, et al. Olaparib monotherapy in patients with advanced cancer and a germline BRCA1/2 mutation. J Clin Oncol. 2015;33:244-50.

20. Matulonis UA, Penson RT, Domchek SM, et al. Olaparib monotherapy in patients with advanced relapsed ovarian monotherapy in patients with advanced relapsed ovarian
cancer and a germline BRCA1/2 mutation: a multistudy analysis of response rates and safety. Ann Oncol. 2016;27:1013-9.

21. Kristeleit R, Shapiro GI, Burris HA, et al. A phase I-II study of the oral PARP inhibitor rucaparib in patients with germline BRCA1/2-mutated ovarian carcinoma or other solid tumors. Clin Cancer Res. 2017;23:4095-106

22. Bitler BG, Watson ZL, Wheeler $L$, et al. PARP inhibitors: clinica utility and possibilities of overcoming resistance. Gynecol Oncol. 2017;147:695-704.

23. Dockery LE, Gunderson CC, Moore KN. Rucaparib: the past, present, and future of a newly approved PARP inhibitor for ovarian cancer. Onco Targets Ther. 2017;10:3029-37.

24. Pujade-Lauraine E, Ledermann JA, Penson RT, et al. Treatment with olaparib monotherapy in the maintenance setting significantly improves progression-free survival in patients with platinum-sensitive relapsed ovarian cancer: results from the phase III SOLO2 study. Gynecol Oncol. 2017;145,1(Suppl):219-20.

25. Tesaro Inc. Zejula (niraparib) prescribing information, 2017. Available at: www.accessdata.fda.gov/drugsatfda_docs/ label/2017/208447lbl.pdf (accessed 16 November 2018)

26. Astra Zeneca Pharmaceuticals LP. Lynparza (olaparib) prescribing information, 2018. Available at: www.accessdata. fda.gov/drugsatfda_docs/label/2018/208558s001lbl.pdf 
(accessed 31 May 2018).

27. Clovis Oncology Inc. Rubraca (rucaparib) prescribing information, 2018. Available at: www.accessdata.fda.gov drugsatfda_docs/label/2018/209115s003lbl.pdf (accessed 16 November 2018)

28. Astra Zeneca AB. Lynparza (olaparib) summary of product characteristics, 2017. Available at: https://ec.europa.eu/health/ documents/community-register/2014/2014121613023 anx_130230_en.pdf (accessed 17 December 2018).

29. Clovis Oncology UK Ltd. Rubraca (rucaparib) summary of product characteristics, 2018. Available at: www.ema.europa. eu/documents/product-information/rubraca-epar-productinformation_en.pdf (accessed 16 November 2018).

30. Eisenhauer EA, Therasse P, Bogaerts J, et al. New response evaluation criteria in solid tumours: revised RECIST guideline (version 1.1). Eur J Cancer. 2009;45:228-47.

31. Ledermann J, Harter P, Gourley C, et al. Supplementary appendix to: Olaparib maintenance therapy in platinumsensitive relapsed ovarian cancer. N Eng/ J Med. 2012;366:1382-92

32. Ledermann JA, Harter P, Gourley C, et al. Quality of life during olaparib maintenance therapy in platinum-sensitive relapsed serous ovarian cancer. Br I Cancer. 2016:115:1313-20.

33. Friedlander M, Matulonis U, Gourley C, et al. Long-term efficacy, tolerability and overall survival in patients with platinumsensitive, recurrent high-grade serous ovarian cancer treated with maintenance olaparib capsules following response to chemotherapy. Br J Cancer. 2018;119:1075-85

34. Pujade-Lauraine E, Ledermann JA, Selle F, et al. Supplementary appendix to: Olaparib tablets as maintenance therapy in patients with platinum-sensitive, relapsed ovarian cancer and a BRCA1/2 mutation (SOLO2/ENGOT-OV21): a double-blind, randomised, placebo-controlled, phase 3 trial. Lancet oncol. 2017; 18:1274-84.

35. Oza A, Combe P, Ledermann J, et al. Evaluation of tumour responses and olaparib efficacy in platinum-sensitive relapsed ovarian cancer patients with or without measurable disease in the SOLO2 trial (ENGOT OV-21) (Abstract 5033, poster 965P). Presented at: European Society for Medical Oncology (ESMO), Madrid, Spain, 8-12 September 2017.

36. Friedlander M, Gebski V, Gibbs E, et al. Health-related quality of life and patient-centred outcomes with olaparib maintenance after chemotherapy in patients with platinum-sensitive, relapsed ovarian cancer and a BRCA1/2 mutation (SOLO2/ ENGOT OV-21): a placebo-controlled, phase 3 randomised trial. Lancet Oncol. 2018;19:1126-34.

37. Mirza MR, Monk BJ, Herrstedt J, et al. Supplementary appendix to: Niraparib maintenance therapy in platinum-sensitive, recurrent ovarian cancer. N Engl J Med. 2016;375:2154-64

38. Tesaro, Inc. Tesaro announces presentation of niraparib phase 3 ENGOT-OV16/NOVA trial secondary endpoint results during SGO 2017. Available at: www.globenewswire.com/ news-release/2017/03/13/935083/0/en/Tesaro-Announcesnews-release/2017/03/13/935083/0/en/Tesaro-AnnouncesSecondary-Endpoint-Results-During-SGO.html (accessed 19 Secondary
July 2019).

39. Mahner S, Mirza MR, Moore K. ENGOT-OV16/NOVA: results of secondary efficacy endpoints of niraparib maintenance therapy in ovarian cancer. Presented at: Society of Gynecologic Oncology (SGO) Annual Meeting on Women's Cancer, National Harbor, Maryland, USA, 12-15 March 2017.

40. Oza AM, Matulonis UA, Malander S, et al. Quality of life in patients with recurrent ovarian cancer treated with niraparib versus placebo (ENGOT-OV16/NOVA): results from a doubleblind, phase 3 , randomised controlled trial Lancet oncol. 2018:19:1117-25.

41. Matulonis UA, Walder L, Nøttrup TJ. Time without symptoms or toxicity in patients with recurrent ovarian cancer receiving niraparib maintenance treatment versus placebo: a TWIST analysis of the ENGOT-OV16/NOVA trial. Gynecol Oncol. 2019:154(Suppl 1):2.

42. Mirza MR, Walder L, Monk BJ, et al. A time without symptoms or toxicity analysis of niraparib compared with routine surveillance in the maintenance treatment of patients with recurrent ovarian cancer. Value Health. 2018;21(Suppl 3):S16.

43. Clovis Oncology. Clovis Oncology presents patient-centered outcomes data from phase 3 ARIEL3 study for Rubraca in advanced ovarian cancer, 2019. Available at: https:// ir.clovisoncology.com/investors-and-news/news-releases/ press-release-details/2019/Clovis-Oncology-Presents-PatientCentered-Outcomes-Data-from-Phase-3-ARIEL3-Study-forRubraca-in-Advanced-Ovarian-Cancer/default.aspx (accessed 21 June 2019).

44. Coleman RL Oza AM, Lorusso D, et al. Exploratory analysis of the effect of maintenance rucaparib on postprogression outcomes in patients with platinum-sensitive recurrent ovaria carcinoma and updated safety data from the phase 3 stud ARIEL3. J Clin Oncol. 2019;37(Suppl 15):5522.

45. Ledermann JA, Harter P, Gourley C, et al. Overall survival in patients with platinum-sensitive recurrent serous ovarian cancer receiving olaparib maintenance monotherapy: an updated analysis from a randomised, placebo-controlled double-blind, phase 2 trial. Lancet Oncol. 2016;17:1579-89.

46. Berek JS, Matulonis UA, Peen U, et al. Safety and dose modification for patients receiving niraparib. Ann Oncol. 2018;29:1784-92.

47. Mirza MR Rapid adjustment of dose to reduce adverse reactions (RADAR) analysis. Presented at: European Society for Gyneacological Oncology, Vienna, Austria, 4-7 November 2017.

48. Gonzalez-Martin A, Mirza MR, Vergote I, et al. A prospective evaluation of tolerability of niraparib dosing based upon baseline body weight and platelet count: blinded pooled interim safety data from the PRIMA/ENGOT-OV26/GOG-3012 study. Ann Oncol. 2018;29(Suppl_8):941PD.

49. Monk BJ, Mirza MR, vergote I, et al. A prospective evaluation of tolerability of niraparib dosing based upon baseline body weight and platelet count: blinded pooled interim safety data from the PRIMA/ENGOT-OV26/GOG-3012 study. Presented at: Society of Gynecologic Oncology (SGO) 50th Annual Meeting on Women's Cancer, Honolulu, Hawaii, USA, 16-19 March 2019.

50. Moore KN, Mirza MR, Matulonis UA. The poly (ADP ribose) polymerase inhibitor niraparib: management of toxicities Gynecol Oncol. 2018:149:214-20.

51. Murai J, Huang SY, Das BB, et al. Trapping of PARP1 and PARP2 by clinical PARP inhibitors. Cancer Res. 2012;72:5588-99.

52. Wahlberg E, Karlberg T, Kouznetsova E, et al. Family-wide chemical profiling and structural analysis of PARP and tankyrase inhibitors. Nat Biotechnol. 2012;30:283-8.

53. Tesaro Inc. Zejula (niraparib) summary of product characteristics, 2017. Available at: www.ema.europa.eu/docs/en_GB/ document_library/EPAR__Product_Information/human/004249/ WC500239289.pdf (accessed 16 November 2018).

54. Kikuchi R, Lao Y, Bow DA, et al. Prediction of clinical drugdrug interactions of veliparib (ABT-888) with human renal transporters (OAT1, OAT3, OCT2, MATE1, and MATE2K). J Pharm SCi. 2013;102:4426-32.

55. McCormick A, Swaisland $\mathrm{H}$. In vitro assessment of the roles of drug transporters in the disposition and drug-drug interaction potential of olaparib. Xenobiotica. 2017:47:903-15.

56. Astra Zeneca. Lynparza significantly delays disease progression in phase III 1st-line SOLO-1 trial for ovarian cancer. Available at: www astrazeneca com/media-centre/press-releases/2018 lynparza-significantly-delays-disease-progression-in-phaseiii-1st-line-solo-1-trial-for-ovarian-cancer.html (accessed 16 November 2018)

57. Moore K, Colombo N, Scambia G, et al. Maintenance olaparib in patients with newly diagnosed advanced ovarian cancer. N Engl J Med. 2018;379:2495-505.

58. Markman M. The current status of PARP inhibitors in ovarian cancer. J Target Ther Cancer. Available at: www.targetedonc. com/publications/targeted-therapies-cancer/2017/2017august/the-current-status-of-parp-inhibitors-in-ovarian-cancer (accessed 19 July 2019).

59. Pujade-Lauraine E, Colombo N, Glasspool R, et al. OReO/ENGOT OV-38: a phase IIIb trial of olaparib maintenance retreatment in patients with epithelial ovarian cancer. Ann Oncol. 2017;28(Suppl 5):987TiP.

60. McCann KE. Novel poly-ADP-ribose polymerase inhibitor combination strategies in ovarian cancer. Curr Opin Obstet Gynecol. 2018;30:7-16.

61. Yap TA, Plummer R, Azad NS, et al. The DNA damagin revolution: PARP inhibitors and beyond. Am Soc Clin Oncol Educ Book. 2019;39:185-95.

62. Gadducci A, Guerrieri ME. PARP inhibitors alone and in combination with other biological agents in homologous recombination deficient epithelial ovarian cancer: from the basic research to the clinic. Crit Rev Oncol Hematol. 2017:114:153-65.

63. American Association for Cancer Research. Mechanism of cediranib/olaparib combo revealed. Cancer Discov. 2019;9:990-1.

64. Kaplan AR, Gueble SE, Liu Y, et al. Cediranib suppresses homology-directed DNA repair through down-regulation of BRCA1/2 and RAD51. Sci Trans/ Med. 2019;11.

65. Strickland KC, Howitt BE, Shukla SA, et al. Association and prognostic significance of BRCA1/2-mutation status with neoantigen load, number of tumor-infiltrating lymphocytes and expression of PD-1/PD-L1 in high grade serous ovarian cancer. Oncotarget. 2016;7:13587-98.

66. Nguyen M, Robillard L, Lin KK, et al. The PARP inhibitor rucaparib activates the STING pathway and enhances antitumor responses of immune checkpoint inhibitors in BRCA deficient syngeneic models. Cancer Res. 2018:78(Suppl 13):1716.

67. Hope IM Chen I Wainszelbaum M et al OVARIO: the phase 2 , single-arm, open-label study of maintenance therapy with iraparib + bevacizumab in patients with advanced ovarian cancer following response on frontline platinum-based chemotherapy. J Clin Oncol. 2018;36(Suppl 15):TPS5606.

68. Monk BJ, Coleman RL, Fujiwara K, et al. ATHENA (GOG-3020/ ENGOT-OV45): a randomised, double-blind, placebo-controlled, phase 3 study of rucaparib + nivolumab following front-line platinum-based chemotherapy in ovarian cancer. Presented at: International Gyynecologic Cancer Society Biennial Meeting, Kyoto, Japan, 14-16 September 2018

69. Ray-Coquard I, Selle F, Harter P, et al. PAOLA-1: an ENGOT/ GCIG phase III trial of olaparib versus placebo combined with bevacizumab as maintenance treatment in patients with advanced ovarian cancer following first-line platinum-based chemotherapy plus bevacizumab. J Clin Oncol. 2016;34(Suppl 15):TPS5607.

70. Onc Live. Phase III avelumab trial discontinued in frontline ovarian cancer. 2019. Available at: www.onclive.com/webexclusives/phase-iii-avelumab-trial-discontinued-in-in-frontlineovarian-cancer (accessed 20 August 2019).

71. Geenen JJ, Linn SC, Beijnen JH, et al. PARP inhibitors in the treatment of triple-negative breast cancer. Clin Pharmacokinet. 2017; 57:427-37

72. Golan T, Hammel P, Reni M, et al. Maintenance olaparib for germline BRCA-mutated metastatic pancreatic cancer. N Eng/ J Med. 2019;381:317-27.

73. Grivas P, Nepert DL, Wride K, et al. ATLAS: a phase 2, open-label study of rucaparib in patients (pts) with locally advanced or metastatic urothelial carcinoma (mUC). J Clin Oncol. 2018;36(Suppl 15):TPS4592.

74. Lim JSJ, Tan DSP. Understanding resistance mechanisms and expanding the therapeutic utility of PARP inhibitors. Cancers (Basel). 2017.9 doi: 10.3390/cancers9080109.

75. Plummer R, Lorigan P, Steven N, et al. A phase II study of the potent PARP inhibitor, rucaparib (PF-01367338, AG014699), with temozolomide in patients with metastatic melanoma demonstrating evidence of chemopotentiation. Cancer Chemother Pharmacol. 2013;71:1191-9.

76. Ramakrishnan Geethakumari P, Schiewer MJ, Knudsen KE, et al. PARP inhibitors in prostate cancer. Curr Treat Options Oncol. 2017; 18:37

77. Shall S, Gaymes T, Farzaneh F, et al. The use of PARP inhibitors in cancer therapy: use as adjuvant with chemotherapy or radiotherapy, use as a single agent in susceptible patients, and techniques used to identify susceptible patients. Methods Mol Biol. 2017:1608:343-70

78. Spigel DR. PARP inhibitors in lung cancer I Thorac Oncol. 2012; $7:$ S392-3

79. Tangutoori S, Baldwin P, Sridhar S. PARP inhibitors: a new era of targeted therapy. Maturitas. 2015;81:5-9.

80. Wang C, Jette N, Moussienko D, et al. ATM-deficient colorectal cancer cells are sensitive to the PARP inhibitor olaparib. Trans/ Oncol. 2017;10:190-6

81. Zhao L, So CW. PARP-inhibitor-induced synthetic lethality for acute myeloid leukemia treatment. Exp Hematol. 2016;44:902-7. 